\title{
LOW-SOURCE-TEMPERATURE DIFFUSION ABSORPTION REFRIGERATION. PART II: EXPERIMENTS AND MODEL ASSESSMENT
}

\author{
Alexander S. Rattner ${ }^{(a)}$, Srinivas Garimella ${ }^{(a)^{*}}$ \\ ${ }^{(a)}$ George W. Woodruff School of Mechanical Engineering \\ Georgia Institute of Technology, Atlanta GA, 30318
}

\section{*Corresponding author:}

Email: sgarimella@gatech.edu Phone: 1-404-894-7479 Fax: 1- 404-894-8496

Address: 801 Ferst Drive, Love Building Room 340, Atlanta, GA 30332, USA

\begin{abstract}
The diffusion absorption refrigeration cycle can enable passive fully thermally activated refrigeration for off-grid applications. In the accompanying paper, a new system configuration was proposed that employs alternate working fluids $\left(\mathrm{NH}_{3}-\mathrm{NaSCN}-\mathrm{He}\right)$, a coupling-fluid heated bubble-pump generator, and an enhanced absorber. Detailed component and system level models were formulated for this design. In Part II of this work, the subject of this paper, these results are applied to implement a complete low-source-temperature $\left(110-130^{\circ} \mathrm{C}\right)$ passively cooled diffusion absorption refrigeration (DAR) system. Cooling was achieved at temperature ranges suitable for refrigeration $\left(T_{\text {evap }}=6 \rightarrow 3^{\circ} \mathrm{C}, \mathrm{COP} \sim 0.06\right)$ and air-conditioning $\left(12 \rightarrow 8^{\circ} \mathrm{C}, \mathrm{COP} \sim\right.$ 0.14). Device performance was also assessed at elevated ambient temperatures, reduced ambient air velocities, and varying system pressures. Results from this investigation agreed well with the predictions of the models developed in Part I.
\end{abstract}

\section{KEYWORDS}

Diffusion absorption refrigeration; absorption; bubble pump; heat and mass transfer 


\section{NOMENCLATURE}

AAD average absolute deviation

CAVP closest approach vapor pressure $(\mathrm{kPa})$

CAT closest approach temperature $(\mathrm{K})$

COP coefficient of performance $Q_{\text {evap }} / Q_{\mathrm{BPG}}$ or $Q_{\text {evap }} / Q_{\mathrm{BPG}, \mathrm{CF}}$

$c_{\mathrm{p}} \quad$ specific heat at constant pressure $\left(\mathrm{kJ} \mathrm{kg} \mathrm{K}^{-1}\right)$

$D \quad$ diameter $(\mathrm{m})$

$g \quad$ gravitational acceleration $\left(9.81 \mathrm{~m} \mathrm{~s}^{-2}\right)$

$H \quad$ height (m)

$i \quad$ enthalpy $\left(\mathrm{kJ} \mathrm{kg}^{-1}\right)$, or segment number

ID inner diameter (m)

$L \quad$ length (m)

LMPD log-mean vapor pressure difference $(\mathrm{kPa})$

LMTD log-mean temperature difference $(\mathrm{K})$

$m \quad$ mass flow rate $\left(\mathrm{kg} \mathrm{s}^{-1}\right)$

$n \quad$ number of measurements, or tubes

OD outer diameter (m)

$p \quad$ pressure $(\mathrm{Pa})$

$p_{\mathrm{v}} \quad$ vapor pressure $(\mathrm{kPa})$

$Q \quad$ heat transfer rate (W)

$R \quad$ thermal resistance $\left(\mathrm{K} \mathrm{W}^{-1}\right)$

$S_{\mathrm{r}} \quad$ submergence ratio (reservoir height / bubble pump height)

$T$ temperature $\left({ }^{\circ} \mathrm{C}\right)$

$U \quad$ velocity $\left(\mathrm{m} \mathrm{s}^{-1}\right)$

UA overall heat transfer conductance $\left(\mathrm{W} \mathrm{K}^{-1}\right)$

UA* overall mass transfer conductance $\left(\mathrm{kg} \mathrm{Pa}^{-1} \mathrm{~s}^{-1}\right)$

$V \quad$ volumetric flow rate $\left(\mathrm{ml} \mathrm{min}^{-1}\right)$

$W F \quad$ wetting factor (liquid film coverage of surface)

\section{Greek characters}

$\delta \quad$ thickness (of liquid film)

$\varepsilon \quad$ heat exchanger effectiveness

$\xi \quad$ auxiliary gas $(\mathrm{He})$ mass fraction in gas mixture

$\rho \quad$ mass density $\left(\mathrm{kg} \mathrm{m}^{-3}\right)$

$\psi \quad$ absorbent mass fraction in solution

\section{Subscripts}

abs

$\mathrm{amb}$

aux

BPG

$\mathrm{CF}$

cool

cond

CS

$\mathrm{DS}$ absorber component

ambient value

auxiliary gas mixture

bubble-pump generator

coupling fluid

cool stream value, or cooling delivery temperature

condenser component

absorbent-concentrated solution stream

absorbent-dilute solution stream 


\begin{tabular}{|c|c|}
\hline evap & value for evaporation phase change, or evaporator \\
\hline $\exp$ & experimental value \\
\hline ext & external value \\
\hline fin & fin value \\
\hline G & gas phase \\
\hline GHX & gas heat exchanger \\
\hline $\mathrm{i}$ & inner value \\
\hline in & inlet value \\
\hline int & internal value \\
\hline $\mathrm{L}$ & liquid phase \\
\hline loss & heat loss (to surroundings) \\
\hline LV & liquid-to-vapor change \\
\hline $\bmod$ & model value \\
\hline net & total value \\
\hline $\mathrm{NH}_{3}$ & pure ammonia value \\
\hline $\mathrm{NH}_{3}-\mathrm{NaSCN}$ & sodium thiocyanate \\
\hline o & outer value \\
\hline out & outlet value \\
\hline ref & refrigerant flow value \\
\hline res & value in liquid reservoir \\
\hline row & tube row \\
\hline sat & saturation conditions \\
\hline SHX & solution heat exchanger \\
\hline sol & solution flow value \\
\hline source & heat source \\
\hline sub & subcooler component \\
\hline sys & system value (pressure) \\
\hline tube & per-tube or tube-wall value \\
\hline $\mathrm{V}$ & vapor phase \\
\hline
\end{tabular}




\section{INTRODUCTION}

In the accompanying paper (Rattner and Garimella, 2015b), fully passive low-sourcetemperature $\left(T_{\text {source }} \leq 130^{\circ} \mathrm{C}\right)$ diffusion absorption refrigeration (DAR) at $T_{\text {cool }}{ }^{\wedge} 5^{\circ} \mathrm{C}$ was identified to have considerable potential for a wide range of applications, such as solar-thermalenergy driven vaccine preservation in developing countries and off-grid refrigeration using engine waste heat. Some experimental low-source-temperature DAR systems have been demonstrated (Ben Ezzine et al., 2010; Jakob et al., 2008; Wang, 2012). However, most have required forced liquid flow for absorber and condenser cooling, employed mechanically pumped internal fluid circulation, or operated at elevated evaporator temperatures that are not suitable for refrigeration. Additionally, few component-level design resources are available for DAR components, except for the bubble-pump generator (BPG). Limited experimental validation or assessment has been performed for reported component models.

A detailed design for a fully passive low-source-temperature DAR refrigeration system was proposed by Rattner and Garimella (2015b). The proposed system employs an alternate workingfluid mixture $\left(\mathrm{NH}_{3}-\mathrm{NaSCN}-\mathrm{He}\right.$, conventional systems employ $\left.\mathrm{NH}_{3}-\mathrm{H}_{2} \mathrm{O}-\mathrm{H}_{2} / \mathrm{He}\right)$, a distributed coupling-fluid (CF) heated BPG, and an enhanced absorber. These three modifications enable operation at reduced source temperatures. Additionally, detailed models were formulated for the bubble-pump generator (BPG), condenser, evaporator, absorber, passive circulation gas loop, and overall system.

The objective of the present investigation is to apply the models from the accompanying paper (Rattner and Garimella, 2015b) to develop a complete demonstration-scale DAR system that satisfies the target operating conditions and constraints. The experimental system is evaluated over a range of source temperatures, input heating rates, cooling delivery temperatures, 
ambient temperatures, ambient air-flow velocities, and system pressures. Results from this investigation are employed to assess the component- and system-level models described in Part I. Additionally, insights gained from this experimental study are applied to identify model refinement approaches, fundamental research needs, and pathways to enhance low-sourcetemperature DAR technology.

\section{EXPERIMENTAL FACILITY AND PROCEDURE \\ 2.1 Overview}

The complete experimental DAR system developed and fabricated in this study is presented in Figure 1. Heat input to the BPG is supplied from a mineral oil coupling-fluid (CF) loop, which simulates a low grade thermal source, such as a passive solar thermosyphon. Cooling is delivered from the evaporator to a water CF loop. This configuration is different than would be employed in a conventional refrigeration system in which an insulated compartment is cooled. The CF loop is employed here to enable precise measurement of cooling capacity. The entire facility is stationed inside a ventilation hood with a variable-speed fan drive. This was employed to contain potential working fluid leaks and permit control of ambient air-flow velocity and temperature (with portable space heaters). 


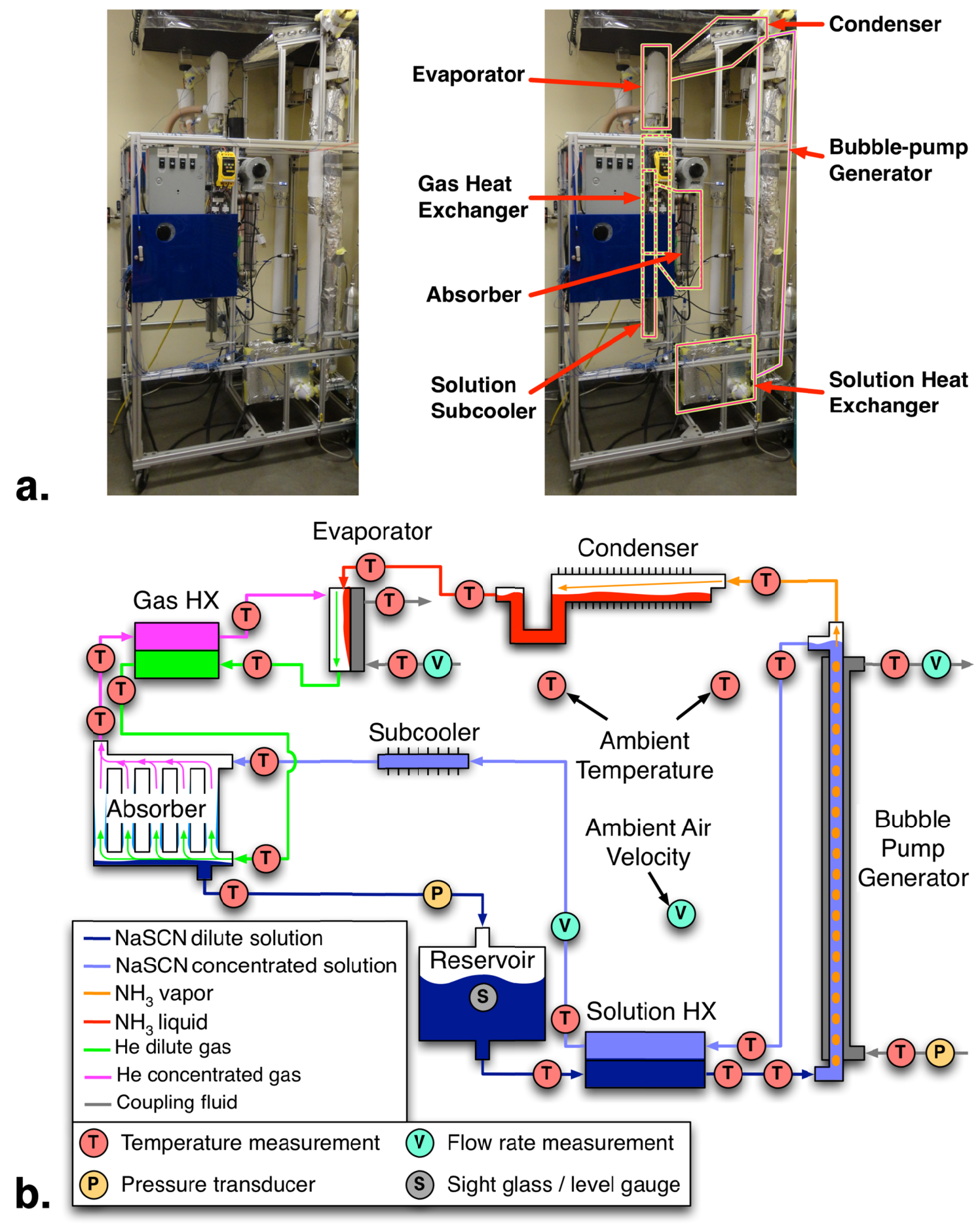

Figure 1 - a. Complete fully passive low-source-temperature diffusion absorption refrigeration system, $\mathbf{b}$. Flow diagram of experimental facility and instrumentation 
Tests were conducted over a primary test matrix for varying BPG heat input rates $\left(Q_{\mathrm{BPG}}=90\right.$ and $120 \mathrm{~W}$, nominal), BPG CF inlet temperatures $\left(T_{\mathrm{BPG}, \mathrm{CF}, \mathrm{in}}=110,120,130^{\circ} \mathrm{C}\right.$, nominal $)$, and evaporator $\mathrm{CF}$ inlet-to-outlet temperature glides $\left(T_{\text {evap, } \mathrm{CF}}=18 \rightarrow 14^{\circ} \mathrm{C}, 12 \rightarrow 8^{\circ} \mathrm{C}, 6 \rightarrow 3^{\circ} \mathrm{C}\right)$. The middle evaporator temperature glide $\left(12 \rightarrow 8^{\circ} \mathrm{C}\right)$ corresponds approximately to airconditioning or chiller operation. The lower temperature glide $\left(6 \rightarrow 3^{\circ} \mathrm{C}\right)$ is representative of maximum acceptable refrigeration temperatures. Evaporator CF temperature glides were maintained by varying the flow rate of a diaphragm metering pump. A smaller temperature glide $(3 \mathrm{~K})$ was selected for the low temperature cases $\left(6 \rightarrow 3^{\circ} \mathrm{C}\right)$, which had reduced cooling rates. This ensured that pump operation did not become very intermittent, which could lead to oscillations in $\mathrm{CF}$ temperature measurements.

For this primary test matrix, the system pressure was nominally $p_{\text {sys }}=1.15 \mathrm{MPa}$ (range of $1.10-1.16 \mathrm{MPa}$ over all 18 cases), dilute solution (DS) concentration was $\psi_{\mathrm{DS}}=0.52$ (range: $0.516-0.539$ ), and ambient air temperature was $25^{\circ} \mathrm{C}$ (range $24.0-25.7^{\circ} \mathrm{C}$ ). The upward ambient air velocity varied over $0.2-0.8 \mathrm{~m} \mathrm{~s}^{-1}$ in the ventilation hood $\left(0.5 \mathrm{~m} \mathrm{~s}^{-1}\right.$ near the condenser and absorber), as measured with a handheld turbine anemometer. Tests were also conducted over smaller auxiliary test matrices to assess off-design system performance with varying ambient temperatures $\left(T_{\mathrm{amb}}=25,27,29^{\circ} \mathrm{C}\right.$, nominal $)$, ambient air-flow rates $\left(U_{\mathrm{amb}}=0.2\right.$ $-0.8 \mathrm{~m} \mathrm{~s}^{-1}, 0.0-0.4 \mathrm{~m} \mathrm{~s}^{-1}, \sim 0 \mathrm{~m} \mathrm{~s}^{-1}$ (not measureable)), and system pressures $\left(p_{\mathrm{sys}}=1.15,1.27\right.$, $1.39 \mathrm{MPa}$ ). These off-design cases were evaluated with nominal $Q_{\mathrm{BPG}}=120 \mathrm{~W}$ (range: $113-$ $122 \mathrm{~W}), T_{\mathrm{BPG}, \mathrm{CF}, \text { in }}=120^{\circ} \mathrm{C}\left(120.0-120.3^{\circ} \mathrm{C}\right.$ range, $130.2^{\circ} \mathrm{C}$ for elevated $p_{\text {sys }}$ cases $)$, and $T_{\text {evap,CF }}$ $=12 \rightarrow 8^{\circ} \mathrm{C}$. The test matrices are summarized in Table 1 .

The ambient temperature range employed in this investigation $\left(25-29^{\circ} \mathrm{C}\right)$ was selected to be representative of typical operating conditions (e.g., room temperature), and is lower than some 


\begin{tabular}{|c|c|c|}
\hline $\begin{array}{l}\text { Evaporator Coupling } \\
\text { Fluid Temperature }\left(T_{\text {evap }, \mathrm{CF}}\right)\end{array}$ & $\begin{array}{c}\text { Bubble Pump Generator } \\
\text { Input Heat }\left(Q_{\mathrm{BPG}}\right)\end{array}$ & $\begin{array}{l}2-0.8 \mathrm{~m} \mathrm{~s}^{-1} \\
\text { Heat Source } \\
\text { Temperature }\left(T_{\mathrm{BPG}, \mathrm{CF}, \mathrm{in}}\right)\end{array}$ \\
\hline $6 \rightarrow 3^{\circ} \mathrm{C}$ & $90 \mathrm{~W}, 120 \mathrm{~W}$ & $110,120,130^{\circ} \mathrm{C}$ \\
\hline $12 \rightarrow 8^{\circ} \mathrm{C}$ & $90 \mathrm{~W}, 120 \mathrm{~W}$ & $110,120,130^{\circ} \mathrm{C}$ \\
\hline $18 \rightarrow 14^{\circ} \mathrm{C}$ & $90 \mathrm{~W}, 120 \mathrm{~W}$ & $110,120,130^{\circ} \mathrm{C}$ \\
\hline \multicolumn{3}{|c|}{$\begin{array}{c}\text { Varying Ambient Temperature } \\
p_{\mathrm{sys}}=1.15 \mathrm{MPa}, \psi_{\mathrm{DS}}=0.52, U_{\mathrm{amb}}=0.2-0.8 \mathrm{~m} \mathrm{~s}^{-1}, T_{\text {evap,CF}}=12 \rightarrow 8^{\circ} \mathrm{C}, Q_{\mathrm{BPG}}=120 \mathrm{~W}, T_{\mathrm{BPG}, \mathrm{CF}, \text { in }}=120^{\circ} \mathrm{C} \\
T_{\mathrm{amb}}=24,27,29^{\circ} \mathrm{C}\end{array}$} \\
\hline \multicolumn{3}{|c|}{$\begin{array}{c}\text { Varying Ambient Air Vertical Velocity } \\
p_{\mathrm{sys}}=1.15 \mathrm{MPa}, \psi_{\mathrm{DS}}=0.52, T_{\mathrm{amb}}=25^{\circ} \mathrm{C}, T_{\text {evap, } \mathrm{CF}}=12 \rightarrow 8^{\circ} \mathrm{C}, Q_{\mathrm{BPG}}=120 \mathrm{~W}, T_{\mathrm{BPG}, \mathrm{CF}, \mathrm{in}}=120^{\circ} \mathrm{C} \\
U_{\mathrm{amb}}=0.2-0.8,0.0-0.4,0 \mathrm{~m} \mathrm{~s}^{-1}\end{array}$} \\
\hline$\psi_{\mathrm{DS}}=0.52, T_{\mathrm{amb}}=25^{\circ} \mathrm{C}, U_{\mathrm{amb}}=$ & $\begin{array}{l}\text { Varying System Pressure } \\
2-0.8 \mathrm{~m} \mathrm{~s}^{-1}, T_{\text {evap, } \mathrm{CF}}=12 \rightarrow 8^{\circ} \mathrm{C}, \\
p_{\text {sys }}=1.15,1.27,1.39 \mathrm{MPa}\end{array}$ & $=120 \mathrm{~W}, T_{\mathrm{BPG}, \mathrm{CF}, \text { in }}=130^{\circ} \mathrm{C}$ \\
\hline
\end{tabular}

residential refrigerator rating protocols $\left(T_{\mathrm{amb}}=32^{\circ} \mathrm{C}\right.$ (United States Department of Energy, 2012) ). This ambient temperature range is also similar to those employed in other low-sourcetemperature experimental DAR studies $\left(27-31^{\circ} \mathrm{C}\right.$ (Jakob et al., 2008), $20^{\circ} \mathrm{C}$ (Ben Ezzine et al., 2010), $10-28^{\circ} \mathrm{C}$ (Wang, 2012)), enabling comparison with related systems.

For each case, the DAR system was first operated at steady state conditions for about $15-30$ minutes. Measurements were then collected every 30 seconds for 15 minutes and averaged to serve as inputs for the data reduction procedures. Descriptions of the individual system components, instrumentation, and data reduction procedures are provided in the following sections.

\subsection{Bubble-pump generator}

The bubble pump generator is a tube-in-tube co-flow heat exchanger (Figure 2). Working fluid $\left(\mathrm{NH}_{3}-\mathrm{NaSCN}\right.$ solution and $\mathrm{NH}_{3}$ vapor) flows vertically upward in an inner stainless steel 


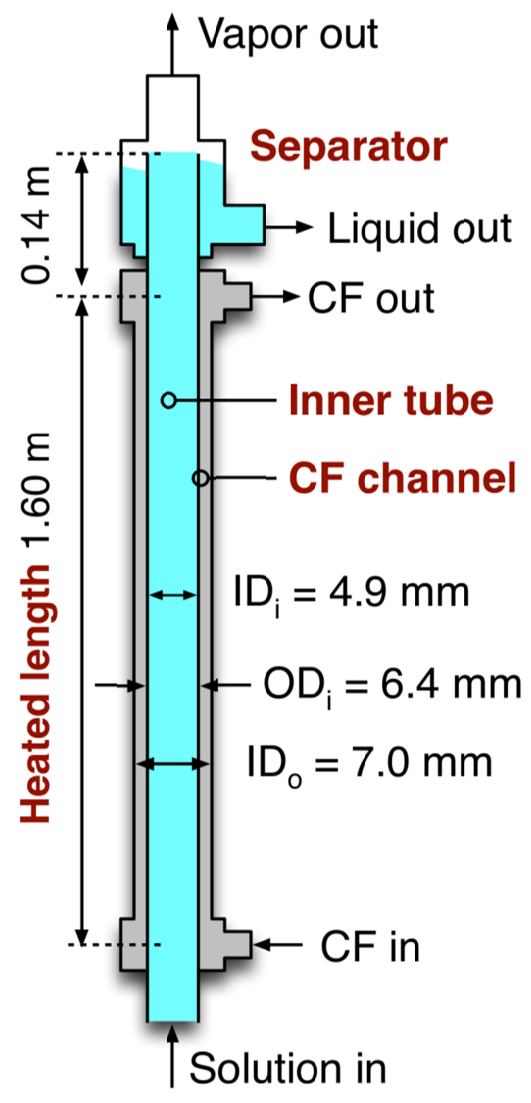

Figure 2- Schematic of bubble-pump generator

tube $\left(\mathrm{ID}_{\mathrm{i}}=4.9 \mathrm{~mm}, \mathrm{OD}_{\mathrm{i}}=6.4 \mathrm{~mm}, L=1.74 \mathrm{~m}\right)$. Heating coupling fluid $(\mathrm{CF})\left(\right.$ Paratherm $\mathrm{NF}^{\circledR}$ mineral oil (Paratherm Corporation, 2013) ) flows through an outer annulus $\left(\mathrm{ID}_{\mathrm{o}}=7.0 \mathrm{~mm}, \mathrm{OD}_{\mathrm{o}}\right.$ =9.5). The lower $1.60 \mathrm{~m}$ portion of the $\mathrm{BPG}$ is heated by the $\mathrm{CF}$, and the upper $0.14 \mathrm{~m}$ penetrates into a settling vessel that separates the liquid and vapor streams. In a recent experimental investigation of CF-heated BPGs with steam-water working fluid (Rattner and Garimella, 2015a), it was found that for fixed overall heat transfer rates, higher heat fluxes near the base of the BPG (solution inlet) resulted in increased liquid pumping rates. This supports the selection of a co-flow BPG configuration, which can yield a greater CF-to-working fluid driving temperature difference near the base than a counter-flow design. The full component is wrapped 
with fiberglass insulation to reduce heat loss to the surroundings. Based on experiments conducted with the inner tube evacuated, the overall thermal resistance from the coupling fluid stream to the ambient ranges over $R_{\mathrm{BPG}, \mathrm{CF}, \mathrm{amb}}=2.0-2.3 \mathrm{~K} \mathrm{~W}^{-1}$, depending on the ambient air velocity in the ventilation hood. A conservative uncertainty of $\pm 25 \%$ is assumed for this thermal resistance.

The solution reservoir level was measured visually with a sight glass. The solution level oscillated during system operation; therefore a conservative uncertainty of $\pm 10 \mathrm{~mm}$ is employed to account for these variations. This corresponds to an uncertainty in the submergence ratio $\left(S_{\mathrm{r}}\right)$ of \pm 0.006 ( $\pm 90 \mathrm{~Pa}$ driving pressure at representative operating conditions). For all cases, $S_{\mathrm{r}}$ was maintained in the range: $0.255-0.280$. The measured submergence ratio does not account for pressure loss in the plumbing and dilute solution side of the solution heat exchanger. Therefore, effective BPG driving pressures are slightly less than $\rho_{\mathrm{L}} g S_{\mathrm{r}} H_{\mathrm{BPG}}$.

Concentrated solution flow rates are measured downstream of the solution heat exchanger (SHX) with an ultrasonic time-of-flight volumetric flow meter (Titan Atrato 700 Series, uncertainty of $\pm 1.0 \%$ of readings). Working fluid inlet and outlet temperatures are measured with calibrated T-type insertion thermocouples $( \pm 0.25 \mathrm{~K}$ uncertainty). The DAR system operating pressure is measured with a Rosemount 2088A absolute pressure transducer (uncertainty $\pm 5.5 \mathrm{kPa}$ ).

The CF volumetric flow rate is measured with a gear flow meter (AW Lake JVM-12KG, \pm $0.3 \mathrm{ml} \mathrm{min}{ }^{-1}$ uncertainty). CF inlet and outlet temperatures are measured with calibrated insertion thermocouples $( \pm 0.25 \mathrm{~K})$. CF properties are determined using data from the Paratherm Corporation (2013). The total heat transfer rate from the CF stream is: 


$$
Q_{\mathrm{BPG}, \mathrm{CF}}=\frac{V_{\mathrm{BPG}, \mathrm{CF}, \text { out }}}{\rho_{\mathrm{BPG}, \mathrm{CF}}\left(T_{\mathrm{BPG}, \mathrm{CF}, \text { out }}\right)}\left[i_{\mathrm{BPG}, \mathrm{CF}}\left(T_{\mathrm{BPG}, \mathrm{CF}, \text { in }}\right)-i_{\mathrm{BPG}, \mathrm{CF}}\left(T_{\mathrm{BPG}, \mathrm{CF}, \text { out }}\right)\right]
$$

Measured CF heat transfer rates vary over $124-161 \mathrm{~W}$ with relatively low propagated uncertainties $( \pm 1.1-3.6 \mathrm{~W})$. Heat transfer to the working fluid is determined, accounting for heat loss from the coupling fluid to the ambient.

$$
\begin{gathered}
Q_{\mathrm{BPG}}=Q_{\mathrm{BPG}, \mathrm{CF}}-Q_{\mathrm{BPG}, \text { loss }} \\
Q_{\mathrm{BPG}, \text { loss }}=\frac{\left(T_{\mathrm{BPG}, \mathrm{CF}, \text { in }}+T_{\mathrm{BPG}, \mathrm{CF}, \text { out }}\right) / 2-T_{\text {amb }}}{R_{\mathrm{BPG}, \mathrm{CF}, \text { amb }}}
\end{gathered}
$$

Here, $\left(T_{\mathrm{BPG}, \mathrm{CF}, \text { in }}+T_{\mathrm{BPG}, \mathrm{CF}, \mathrm{out}}\right) / 2$ is the estimated average coupling fluid channel temperature, and $T_{\mathrm{amb}}$ is the ambient air temperature (averaged over two thermocouples in the enclosing ventilation hood). Measured heat transfer rates to the working fluid $\left(Q_{\mathrm{BPG}}\right)$ range over $89-122$ $\mathrm{W}\left(Q_{\mathrm{BPG}, \text { loss }}=36-47 \mathrm{~W}\right)$. Corresponding uncertainties range over $9-12 \mathrm{~W}$, and are less than $12 \%$ of $Q_{\mathrm{BPG}}$ for all cases. The greater uncertainties for $Q_{\mathrm{BPG}}$ than for $Q_{\mathrm{BPG}, \mathrm{CF}}$ are due to the relatively large uncertainty applied to the heat-loss thermal resistance $( \pm 25 \%)$.

Concentrated solution flow rates range over $26-45 \mathrm{ml} \mathrm{min}^{-1} \pm 1 \%\left(27-45 \mathrm{~g} \mathrm{~min}{ }^{-1}\right)$ for the main test matrix. Flow rates tend to increase with $\mathrm{CF}$ inlet source temperatures. This occurs because greater portions of input heat are transferred near the BPG base with elevated $T_{\mathrm{CF}, \text { in, }}$ increasing average channel void fraction and reducing hydrostatic pressure drop. Flow rates are lower for the two elevated pressure cases $\left(25 \mathrm{ml} \mathrm{min}^{-1}\right.$ at $1.25 \mathrm{MPa}, 19 \mathrm{ml} \mathrm{min}^{-1}$ at $\left.1.39 \mathrm{MPa}\right)$. This occurs because of the greater sensible heating load at elevated pressure (higher $T_{\text {sat }}$ ) and reduced driving temperature difference near the BPG inlet. 
The BPG liquid outlet flow is assumed to be saturated solution. Therefore, the concentrated solution (CS) NaSCN concentrations $\left(\psi_{\mathrm{CS}}\right)$ are determined using the saturation curve formulated by Infante Ferreira (1984) for $\mathrm{NH}_{3}-\mathrm{NaSCN}$ solutions $\left(p_{\mathrm{sys}}=p_{\mathrm{v}, \mathrm{NH} 3-\mathrm{NaSCN}}\left(T_{\mathrm{BP}, \mathrm{out}}, \psi_{\mathrm{CS}}\right)\right)$. The resulting values of $\psi_{\mathrm{CS}}$ range over $0.559-0.622 \pm 0.001 . \psi_{\mathrm{CS}}$ tends to decrease slightly with increasing solution flow rate. This occurs because less refrigerant is generated in these cases for fixed heating rates (greater portions of $Q_{\mathrm{BPG}}$ are used for sensible heating of the solution).

Assuming that the inlet flow to the BPG is subcooled liquid, the dilute solution flow rate $\left(m_{\mathrm{DS}}\right)$, dilute solution concentration $\left(\psi_{\mathrm{CS}}\right)$, and refrigerant vapor generation rate $\left(m_{\mathrm{ref}}\right)$ can be determined by applying mass, species, and energy balances over the BPG.

$$
\begin{gathered}
m_{\mathrm{DS}}=m_{\mathrm{CS}}+m_{\mathrm{ref}} \\
\psi_{\mathrm{DS}} m_{\mathrm{DS}}=\psi_{\mathrm{CS}} m_{\mathrm{CS}} \\
m_{\mathrm{DS}} i_{\mathrm{NH}_{3}-\mathrm{NaSCN}}\left(T_{\mathrm{BPG}, \mathrm{in}}, \psi_{\mathrm{DS}}\right)-m_{\mathrm{CS}} i_{\mathrm{NH}_{3}-\mathrm{NaSCN}}\left(T_{\mathrm{BPG}, \text { out }}, \psi_{\mathrm{CS}}\right)-m_{\mathrm{ref}} i_{\mathrm{NH}_{3}}\left(T_{\mathrm{BPG}, \text { out }}, p_{\mathrm{sys}}\right)=Q_{B P G}
\end{gathered}
$$

The dilute solution flow rates are found to range over $24-49 \pm 0.5-0.6 \mathrm{~g} \mathrm{~min}^{-1}$. Dilute solution concentrations range over $0.513-0.538 \pm 0.006-0.013$. Refrigerant flow rates range over $m_{\text {ref }}=2.5-4.2 \pm 0.5 \mathrm{~g} \mathrm{~min}^{-1}$. The high uncertainty for $m_{\mathrm{ref}}(10-20 \%)$ is due to the relatively large uncertainty in heat loss from the BPG to the ambient. BPG inlet temperatures $\left(T_{\mathrm{BPG}, \text { in }}\right)$ range over $58-70^{\circ} \mathrm{C}$, and outlet temperatures $\left(T_{\mathrm{BPG}, \text { out }}\right)$ over $77-94^{\circ} \mathrm{C}$ (except for the elevated pressure cases: $98.2^{\circ} \mathrm{C}$ at $1.27 \mathrm{MPa}, 106.3^{\circ} \mathrm{C}$ at $1.39 \mathrm{MPa}$ ). 


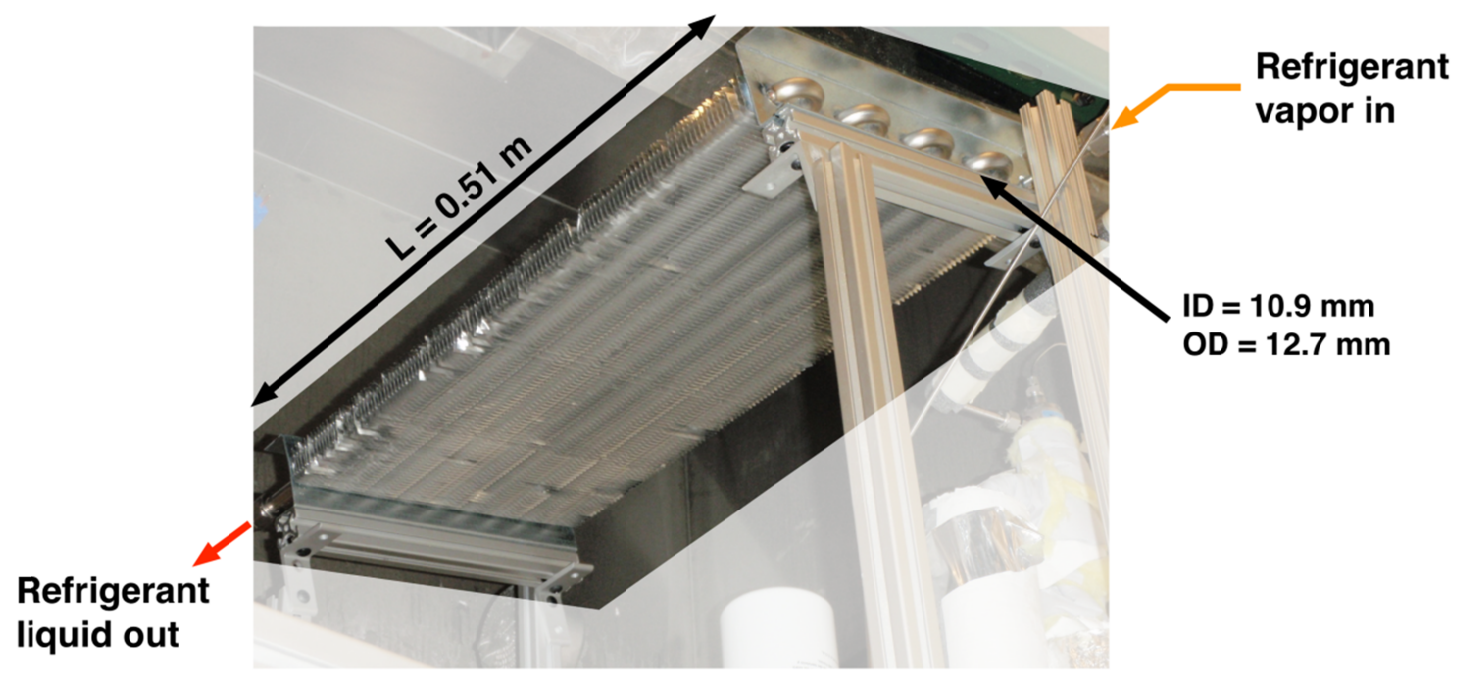

Figure 3 - $\quad$ Serpentine finned-tube condenser

\subsection{Condenser}

A serpentine finned-tube condenser was employed in the DAR system (Figure 3). The component has 9 rows of stainless steel tubes (ID $=10.9 \mathrm{~mm}, \mathrm{OD}=12.7 \mathrm{~mm}, L_{\text {row }}=0.51 \mathrm{~m}, L_{\text {tot }}$ $=4.57 \mathrm{~m}$ ). Tube rows are spaced by $p_{\text {row }}=31.8 \mathrm{~mm}$. The tubes are enhanced with press-fit smooth rectangular fins of thickness $0.19 \mathrm{~mm}$, height $27.5 \mathrm{~mm}$, and pitch $4.2 \mathrm{~mm}$. The condenser is inclined slightly downward (towards the refrigerant outlet) such that condensate drains into the evaporator. A U-tube gas-trap is installed at the condenser outlet to prevent non-condensable helium ingress.

The condenser refrigerant flow rates are determined from the BPG analysis $\left(m_{\mathrm{ref}}=2.5-4.2\right.$ $\left.\pm 0.5 \mathrm{~g} \mathrm{~min}^{-1}\right)$. Condenser inlet temperatures are assumed to be equal to BPG outlet temperatures ( $T_{\text {cond,in }}=T_{\mathrm{BPG}, \text { out }}=77-94^{\circ} \mathrm{C}$ for the main test matrix cases). Condenser outlet temperatures range over $T_{\text {cond,out }}=23.0-27.3^{\circ} \mathrm{C}$, and are generally slightly lower than the average ambient temperatures ( $\sim 1 \mathrm{~K}$ difference). The slightly low condenser outlet temperatures could be due to 


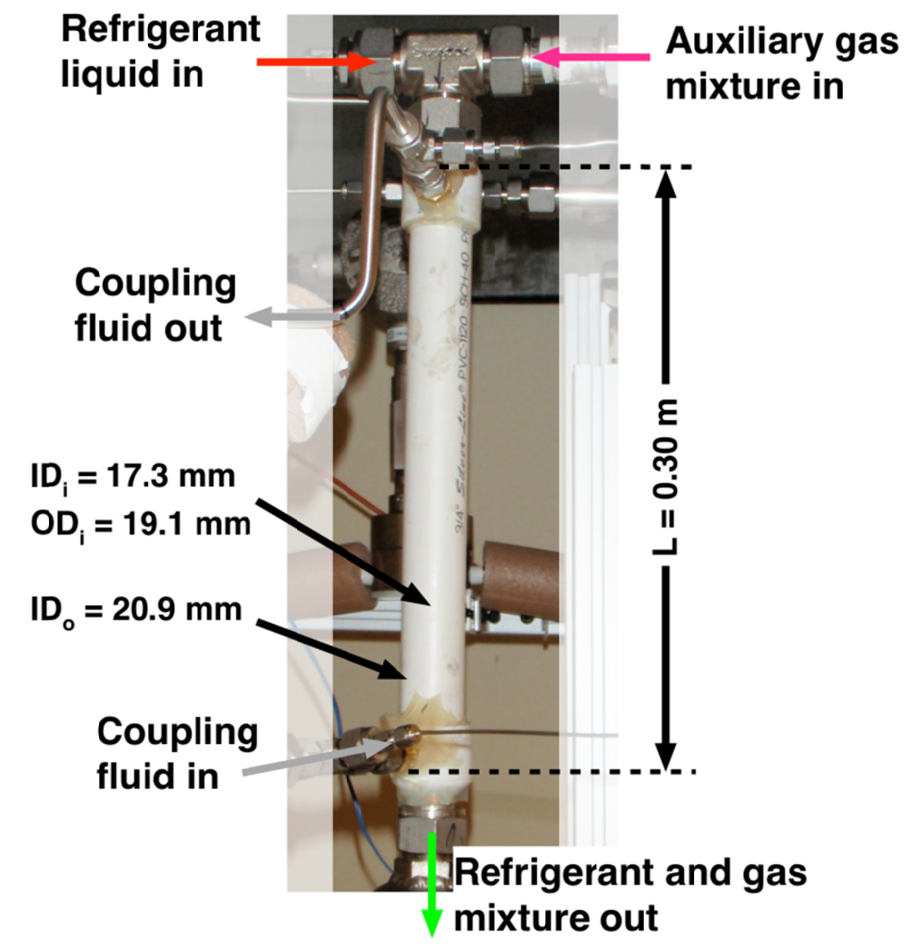

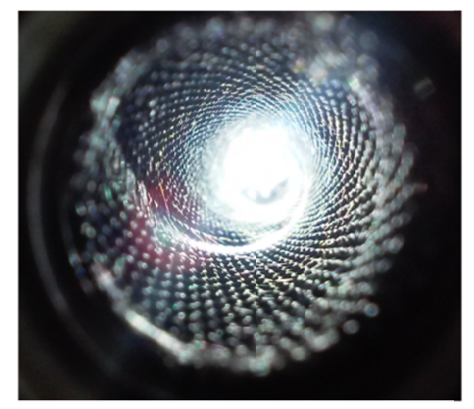

Photograph of inner tube with fiberglass cloth wicking sleeve

Figure $4-\quad$ Tube-in-tube evaporator

variations in local ambient temperature or heat transfer to the cool downstream evaporator. The condenser heat transfer is evaluated as:

$$
Q_{\text {cond }}=m_{\text {ref }}\left[i_{\mathrm{NH}_{3}}\left(T_{\mathrm{BPG}, \text { out }}, p_{\mathrm{sys}}\right)-i_{\mathrm{NH}_{3}}\left(T_{\text {cond,out }}, p_{\mathrm{sys}}\right)\right]
$$

Condenser heat transfer rates vary over $36-93 \pm 11 \mathrm{~W}$. The uncertainty in $Q_{\text {cond }}$ is primarily due to the uncertainty in $m_{\text {ref. }}$ In all measured cases, $T_{\text {cond,out }}$ was less than $T_{\text {sat }}\left(T_{\text {sat }}-T_{\text {cond,out }}=2-\right.$ $6 \mathrm{~K}$ for the primary test matrix), indicating complete condensation.

\subsection{Evaporator}

A tube-in-tube evaporator was used in this investigation (Figure 4). The liquid refrigerant and auxiliary gas contact in a Tee above the evaporator, and drain through the stainless steel evaporator tube $\left(\mathrm{ID}_{\mathrm{i}}=17.3 \mathrm{~mm}, \mathrm{OD}_{\mathrm{i}}=19.1 \mathrm{~mm}, L=0.30 \mathrm{~m}\right)$. Coupling fluid (water) flows 
upward (counter-flow) through an annular channel around the evaporator tube $\left(\operatorname{ID}_{\mathrm{o}}=20.9 \mathrm{~mm}\right)$. The full component is insulated with $\sim 25 \mathrm{~mm}$ of fiberglass wrap. A woven fiberglass sleeve ( $\sim 0.7 \mathrm{~mm}$ thick) is inserted inside the evaporator inner tube to improve film wetting. Heat gain from the ambient is assumed negligible because of the relatively small component size ( $L=0.30$ $\mathrm{m})$ and low average temperature difference $\left(T_{\text {amb }}-T_{\text {evap,CF }} \sim 10-20 \mathrm{~K}\right)$.

Working fluid and CF temperatures are measured at the component inlets and outlets with Ttype insertion thermocouples $( \pm 0.25 \mathrm{~K})$. The coupling fluid is circulated with a diaphragm metering pump (Pulsatron Pulsafeeder LMH6TA-PTC3). The pump was calibrated to ensure accurate $\mathrm{CF}$ flow rates during operation ( $\pm 5 \%$ uncertainty). An electric immersion heater and a chiller-coupled tube-in-tube heat exchanger were installed upstream of the evaporator to control $\mathrm{CF}$ inlet temperatures. The $\mathrm{CF}$ flow rate was adjusted during operation to maintain intended temperature glides $\left(18 \rightarrow 14^{\circ} \mathrm{C}, 12 \rightarrow 8^{\circ} \mathrm{C}, 6 \rightarrow 3^{\circ} \mathrm{C}\right)$. The delivered cooling rate is evaluated as:

$$
Q_{\text {evap }}=V_{\text {evap, }, \mathrm{CF}} \rho_{\text {evap, } \mathrm{CF}} \mathcal{c}_{\mathrm{p}, \text { evap, } \mathrm{CF}}\left(T_{\text {evap,CF,in }}-T_{\text {evap, }, \mathrm{F}, \text { out }}\right)
$$

Evaporator cooling rates varied over $5-21 \mathrm{~W}$ for most cases, with propagated uncertainties of $\pm 1-2 \mathrm{~W}$.

Evaporator inlet auxiliary gas composition is challenging to determine, and was not measured directly in these experiments. An absorber approach ammonia vapor pressure difference was assumed $\left(\mathrm{CAVP}_{\mathrm{abs}}=150 \mathrm{kPa}\right)$ to estimate the composition $\left(p_{\mathrm{v}, \mathrm{aux}}=p \mathrm{v}\right.$, $\mathrm{NH3}-$ $\left.\operatorname{NaSCN}\left(T_{\text {abs,L,in, }}, \psi_{\mathrm{CS}}\right)+\mathrm{CAVP}_{\mathrm{abs}}\right)$. This value is slightly more conservative than predicted in Section 2.5 of Rattner and Garimella $(2015 b)\left(C^{2} V_{a b s}=111 \mathrm{kPa}\right)$ to account for non-uniform flow distribution and incomplete film wetting. The resulting inferred auxiliary gas helium fractions range over $\xi_{\text {aux }}=0.273-0.462$. In future investigations, techniques such as gas 


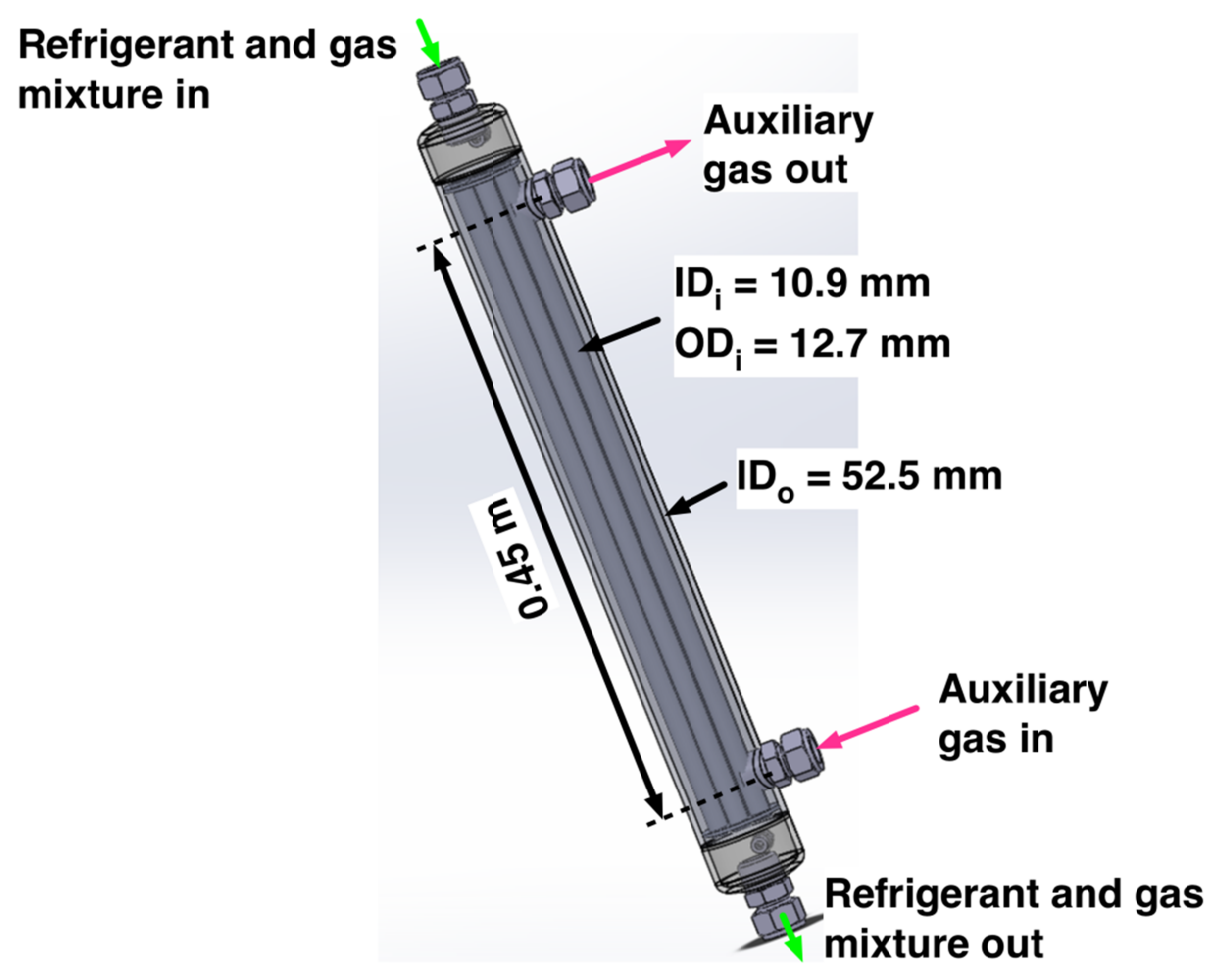

Figure 5 - Shell-and-tube gas heat exchanger

chromatography or ultrasonic time-of-flight measurement could be employed to directly measure gas mixture composition. Auxiliary gas flow rates are inferred from the gas heat exchanger analysis (GHX) described in the next section. The resulting values are determined to range over $m_{\text {aux }}=25-41 \mathrm{~g} \mathrm{~min}^{-1}$ for the different experimental cases.

\subsection{Gas heat exchanger}

A stainless steel shell-and-tube gas heat exchanger was employed in the experimental DAR system (Figure 5). No baffles were installed on the shell side to minimize pressure drop in the passive circulation loop. The evaporator outlet stream flows downward through seven parallel circular tubes $\left(\mathrm{ID}_{\mathrm{i}}=10.9 \mathrm{~mm}, \mathrm{OD}_{\mathrm{i}}=12.7 \mathrm{~mm}, L=0.45 \mathrm{~m}\right)$. The warm auxiliary gas stream rises 
counterflow through the shell side of the GHX $\left(\mathrm{ID}_{\mathrm{o}}=52.5 \mathrm{~mm}\right)$. Temperature measurements were collected at all four GHX ports (T-type thermocouples, $\pm 0.25 \mathrm{~K}$ uncertainty).

No flow meters were commercially available to measure the auxiliary gas stream that satisfied requirements for total working pressure $(1.1-1.4 \mathrm{MPa})$, low pressure drop (natural circulation flow), material compatibility ( $\mathrm{NH}_{3}$ gas), and anticipated low velocities $\left(\sim 0.2 \mathrm{~m} \mathrm{~s}^{-1}\right)$. In future experiments, special-purpose insertion-type thermal anemometers could be employed to accurately measure auxiliary gas flow rates with acceptable pressure drops. Commercially available thermal anemometers are generally configured for higher flow rates, relatively low working pressure (1.0 MPa max), and expose circuitry to the working fluid. The auxiliary gas flow rate $\left(m_{\mathrm{aux}}=m_{\mathrm{abs}, \mathrm{G}, \text { out }}=m_{\mathrm{evap}, \mathrm{G}, \mathrm{in}}\right)$ was inferred based on the design GHX overall conductance $\left(\mathrm{UA}_{\mathrm{GHX}}=2.0 \mathrm{~W} \mathrm{~K}^{-1}\right)$ and inlet and outlet temperature measurements (i.e., $\left.\mathrm{LMTD}_{\mathrm{GHX}}\right)$.

$$
\begin{gathered}
Q_{\mathrm{GHX}}=\mathrm{UA}_{\mathrm{GHX}} \frac{\left(T_{\mathrm{GHX}, \mathrm{o}, \mathrm{in}}-T_{\mathrm{GHX}, \mathrm{i}, \mathrm{out}}\right)-\left(T_{\mathrm{GHX}, \mathrm{o}, \mathrm{out}}-T_{\mathrm{GHX}, \mathrm{ini}}\right)}{\ln \left(\frac{T_{\mathrm{GHX}, \mathrm{o}, \mathrm{in}}-T_{\mathrm{GHX}, \mathrm{iout}}}{T_{\mathrm{GHX}, \mathrm{o}, \mathrm{out}}-T_{\mathrm{GHX}, \mathrm{i}, \mathrm{in}}}\right)} \\
m_{\mathrm{aux}}=\frac{Q_{\mathrm{GHX}}}{c_{\mathrm{p}, \mathrm{aux}}\left(T_{\mathrm{GHX}, \mathrm{o}, \mathrm{in}}-T_{\mathrm{GHX}, \mathrm{o}, \mathrm{out}}\right)}
\end{gathered}
$$

Inferred GHX heat transfer rates range over $13-29 \mathrm{~W}$, yielding auxiliary gas flow rates of $25-41 \mathrm{~g} \mathrm{~min}^{-1}$.

\subsection{Solution heat exchanger}

A stainless steel serpentine counterflow tube-in-tube solution heat exchanger (SHX) is employed in the experimental system (Figure 6). The hot concentrated solution (CS) stream flows through an inner tube $\left(\mathrm{ID}_{\mathrm{i}}=4.6 \mathrm{~mm}, \mathrm{OD}_{\mathrm{i}}=6.4 \mathrm{~mm}, L_{\mathrm{SHX}}=1.34 \mathrm{~m}\right)$. The cooler dilute solution (DS) stream flows through the annular channel $\left(\mathrm{ID}_{\mathrm{o}}=10.9 \mathrm{~mm}, \mathrm{OD}_{\mathrm{o}}=12.7 \mathrm{~mm}\right)$. Inlet 


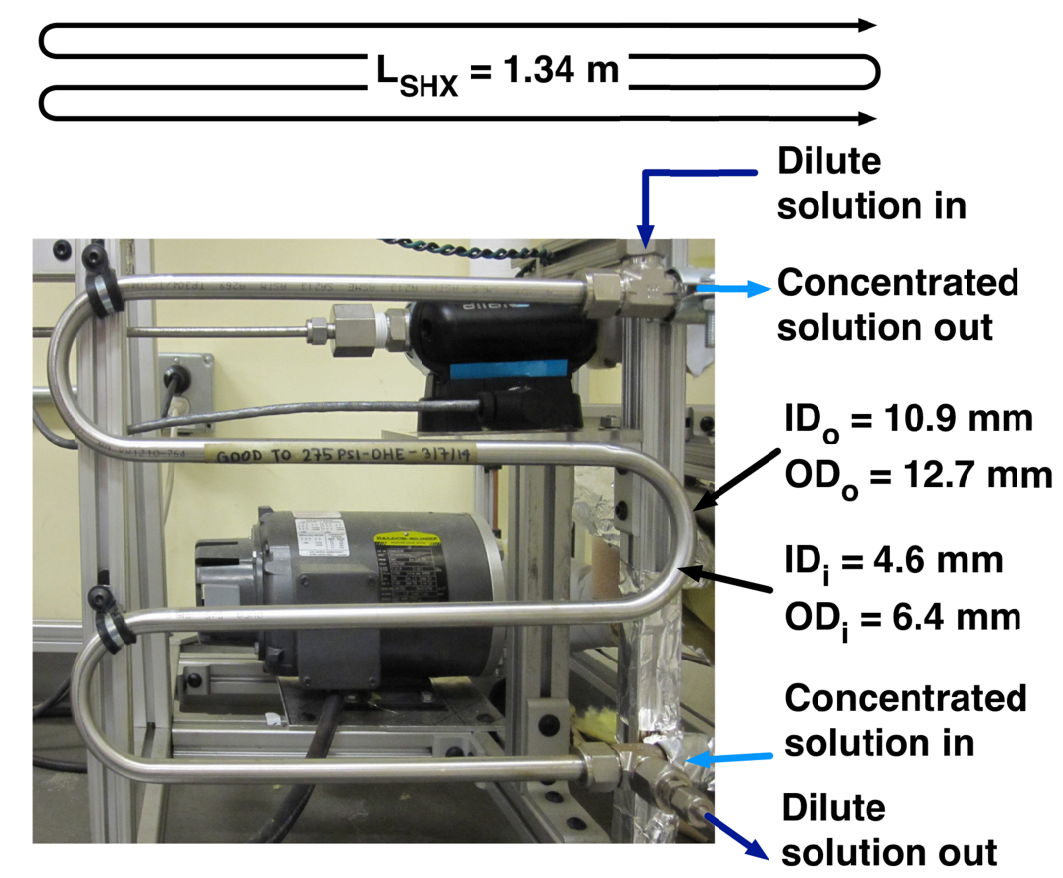

Figure $6-\quad$ Serpentine tube-in-tube counterflow solution heat exchanger

and outlet temperatures are measured for both streams (T-type insertion thermocouples, $\pm 0.25 \mathrm{~K}$ uncertainty). The component is insulated with fiberglass panels ( $\sim 50 \mathrm{~mm}$ thick) to reduce heat loss. The component is rated based on heat transfer to the cooler DS stream.

$$
Q_{\mathrm{SHX}}=m_{\mathrm{DS}}\left[i_{\mathrm{NH}_{3}-\mathrm{NaSCN}}\left(T_{\mathrm{DS}, \text { out }}, \psi_{\mathrm{DS}}\right)-i_{\mathrm{NH}_{3}-\mathrm{NaSCN}}\left(T_{\mathrm{DS}, \mathrm{in}}, \psi_{\mathrm{DS}}\right)\right]
$$

Component heat transfer rates range over $Q_{\mathrm{SHX}}=32-56 \pm 1 \mathrm{~W}$ for the experimental cases. Heat loss from the component is determined based on the overall energy balance.

$$
Q_{\mathrm{SHX}, \text { loss }}=\begin{aligned}
& m_{\mathrm{DS}}\left[i_{\mathrm{NH}_{3}-\mathrm{NaSCN}}\left(T_{\mathrm{DS}, \text { in }}, \psi_{\mathrm{DS}}\right)-i_{\mathrm{NH}_{3}-\mathrm{NaSCN}}\left(T_{\mathrm{DS}, \text { out }}, \psi_{\mathrm{DS}}\right)\right] \\
& +m_{\mathrm{CS}}\left[i_{\mathrm{NH}_{3}-\mathrm{NaSCN}}\left(T_{\mathrm{CS}, \text { in }}, \psi_{\mathrm{CS}}\right)-i_{\mathrm{NH}_{3}-\mathrm{NaSCN}}\left(T_{\mathrm{CS}, \text { out }}, \psi_{\mathrm{CS}}\right)\right]
\end{aligned}
$$

SHX heat loss rates range over $8-18 \pm 1 \mathrm{~W}$. 


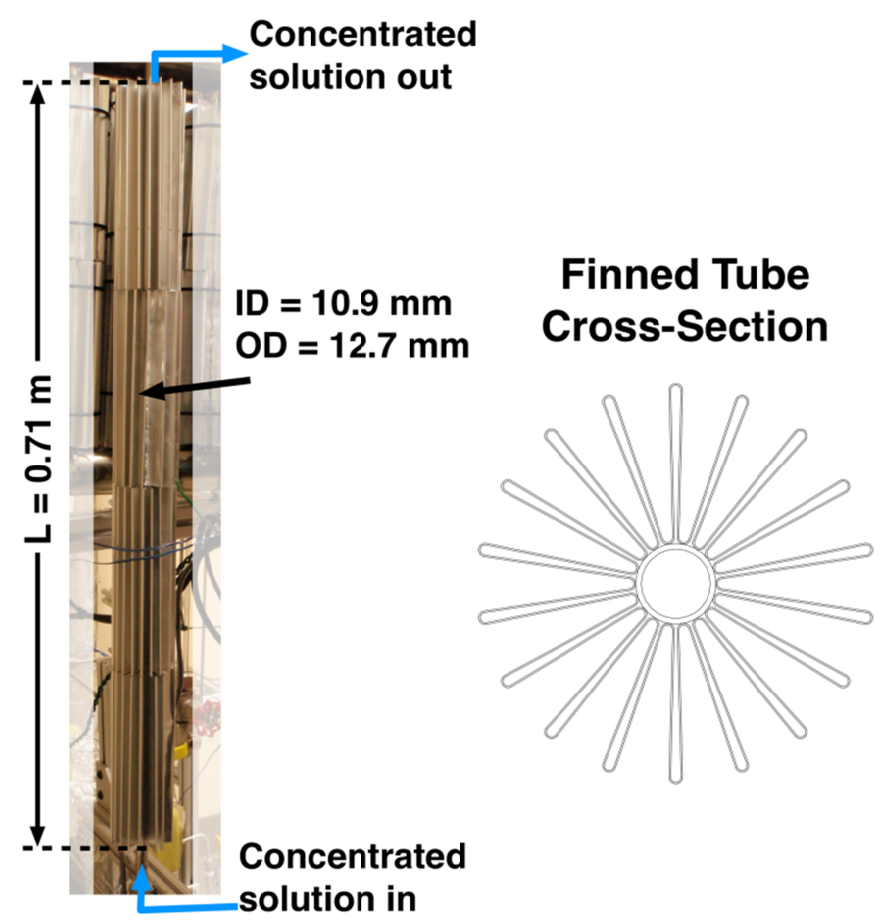

Figure 7 - $\quad$ Passive solution subcooler, main finned section

\subsection{Solution subcooler}

A solution subcooler was installed between the SHX CS outlet and absorber solution inlet (Figure 7). The component design includes a bare horizontal inlet tube section (ID $=4.6 \mathrm{~mm}$, OD $=6.4 \mathrm{~mm}, L=0.46 \mathrm{~m})$, a main vertical finned section $(\mathrm{ID}=10.9 \mathrm{~mm}, \mathrm{OD}=12.7 \mathrm{~mm}, L=0.71$ $\mathrm{m}$ ), and a bare horizontal outlet tube section (ID $=4.6 \mathrm{~mm}, \mathrm{OD}=6.4 \mathrm{~mm}, L=0.23 \mathrm{~m}$ ). The main portion is wrapped with $18 H_{\text {fin }}=25 \mathrm{~mm}$ tall, $\delta_{\text {fin }}=0.35 \mathrm{~mm}$ thick, smooth corrugated aluminum fins. This configuration results in 18 open (outward-facing) channels with average width $\delta_{\mathrm{o}}=5.5$ $\mathrm{mm}$ and 18 closed (inward-facing) channels with average width $3.0 \mathrm{~mm}$. The fins were affixed to the subcooler with an epoxy resin (Loctite $608 \mathrm{Hysol}$, reported thermal conductivity $\sim 0.21 \mathrm{~W} \mathrm{~m}^{-}$ ${ }^{1} \mathrm{~K}^{-1}$ (Loctite Corporation, 2001)). In a separate set of passively air-cooled water-flow experiments, this was found to increase overall heat transfer by $5-20 \%$ compared with affixing fins only with external compression bands. In future investigations, fins could be brazed to the 
subcooler to further reduce thermal contact resistance. Temperature measurements were collected at the component inlet (SHX CS outlet) and outlet (absorber solution inlet). The overall component heat transfer rate and conductance are:

$$
\begin{gathered}
Q_{\text {sub }}=m_{\mathrm{CS}}\left[i_{\mathrm{NH}_{3}-\mathrm{NaSCN}}\left(T_{\text {sub,in }}, \psi_{\mathrm{CS}}\right)-i_{\mathrm{NH}_{3} \text {-NaSCN }}\left(T_{\text {sub,out }}, \psi_{\mathrm{CS}}\right)\right] \\
\mathrm{UA}_{\text {sub }}=Q_{\text {sub }} / \mathrm{LMTD}_{\text {sub,amb }}
\end{gathered}
$$

Here $\mathrm{LMTD}_{\text {sub,amb }}$ is the log-mean temperature difference between the subcooler solution stream and ambient air. The component heat transfer rate varies over $7.4-21.7 \pm 0.7 \mathrm{~W}$. The corresponding conductance range is $\mathrm{UA}_{\text {sub }}=1.5-2.1 \pm 0.1 \mathrm{~W} \mathrm{~K}^{-1}$.

\subsection{Absorber}

The absorber configuration proposed in Section 2.5 of Rattner and Garimella (2015b) was implemented in the experimental facility. In this design, downward flowing $\mathrm{NH}_{3}-\mathrm{NaSCN}$ solution contacts rising $\mathrm{NH}_{3}-\mathrm{He}$ gas in 10 parallel vertical tubes $(\mathrm{ID}=17.3 \mathrm{~mm}, \mathrm{OD}=19.1 \mathrm{~mm}$, $L=0.35 \mathrm{~m}$ ) (Figure 8a-b). Each tube is wrapped with twelve $25 \mathrm{~mm}$ tall, $0.35 \mathrm{~mm}$ thick, smooth corrugated aluminum fins. The fins are affixed to the absorber with epoxy resin, as in the solution subcooler. Liquid is distributed to the absorber tubes from a horizontal U-tube header (Figure 8c). The absorber tubes penetrate $12.7 \mathrm{~mm}$ into the header. Each tube top is slotted, and stranded stainless steel "feed wires" are installed to wick liquid from the solution pool in the header (Figure 8d). This design was experimentally evaluated with ambient pressure water flow, and was found to result in more uniform liquid distribution than with plain tubes. To improve internal film wetting, helical wire coils were inserted into the absorber tubes (wire diameter 0.6 $\mathrm{mm})$. 

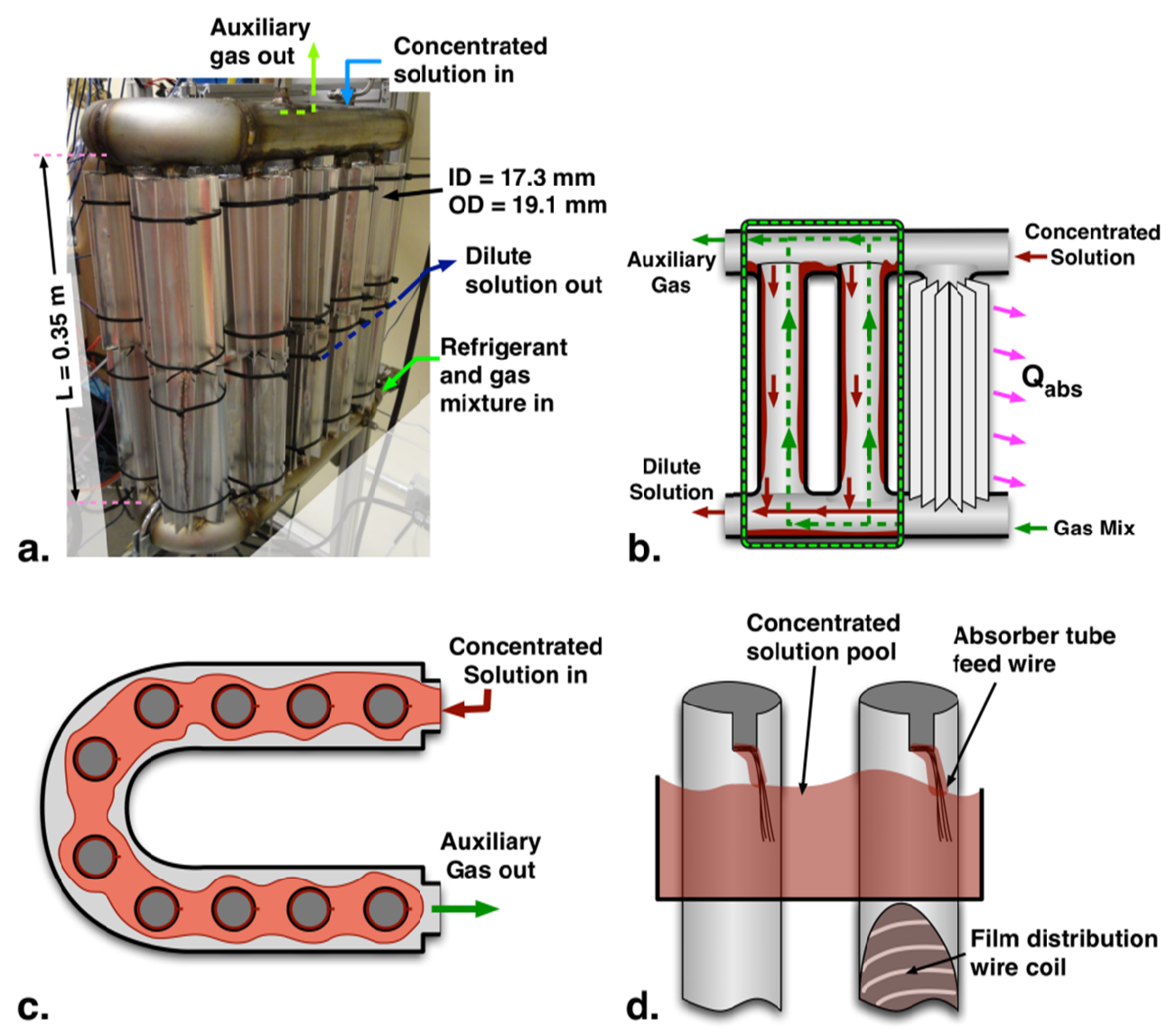

Figure 8 - a. Enhanced parallel finned-tubed counter-flow absorber, b. Vertical section-view schematic of absorber showing contacting of downward flowing solution film and rising gas mixture, c. Horizontal sectionview schematic of upper U-tube header showing solution distribution to absorber tubes, d. Detail view of Feed-wire wicking solution distribution mechanism and coil inserts to enhance film wetting

T-type insertion thermocouples $( \pm 0.25 \mathrm{~K}$ uncertainty) were installed in all four absorber inlet and outlet ports. However, the auxiliary gas flow rate and concentration (absorber gas outlet) could not be directly measured in experiments (see Sections $2.4-2.5$ ). Similarly, the refrigerantgas mixture may enter the absorber in a two-phase state with unknown quality. Therefore, the absorber heat rejection rate $\left(Q_{\text {abs }}\right)$ is determined from an energy balance applied over the entire gas loop (evaporator, GHX, absorber, and connective plumbing). 
$Q_{\mathrm{abs}}=m_{\mathrm{CS}} i_{\mathrm{NH}_{3}-\mathrm{NaSCN}}\left(T_{\mathrm{abs}, \mathrm{L}, \mathrm{in}}, \psi_{\mathrm{CS}}\right)-m_{\mathrm{DS}} i_{\mathrm{NH}_{3}-\mathrm{NaSCN}}\left(T_{\text {abs }, \mathrm{L}, \mathrm{out}}, \psi_{\mathrm{CS}}\right)+m_{\mathrm{ref}} i_{\mathrm{NH}_{3}}\left(T_{\text {evap }, \mathrm{L}, \mathrm{in}}, p_{\mathrm{sys}}\right)+Q_{\text {evap }}$

In this energy balance, heat transfer between the ambient and the gas-loop plumbing and exterior of the GHX is included in $\mathrm{Q}_{\mathrm{abs}}$. However, the flows contained in these volumes are typically close to the ambient temperature; therefore, such contributions to $Q_{\text {abs }}$ are expected to be small. The resulting absorber heat transfer rates range over $Q_{\text {abs }}=-6.3-12.4 \pm 1-2 \mathrm{~W}$. These values are relatively low in magnitude, and are negative in some cases due to sensible heating of the refrigerant-gas mixture and solution.

\subsection{Complete DAR system}

The full DAR system is rated using the cooling coefficient of performance (COP). An external COP is defined with respect to total heat transfer from the BPG CF.

$$
\mathrm{COP}_{\text {ext }}=Q_{\text {evap }} / Q_{\mathrm{BPG}, \mathrm{CF}}
$$

Representative external COP values for the main test matrix are: $\sim 0.05 \pm 0.006\left(T_{\text {evap,CF }}=6\right.$ $\left.\rightarrow 3^{\circ} \mathrm{C}\right), \sim 0.09 \pm 0.01\left(12 \rightarrow 8^{\circ} \mathrm{C}\right), \sim 0.11 \pm 0.01\left(18 \rightarrow 14^{\circ} \mathrm{C}\right)$.

Internal COPs are evaluated based on only accounting for heat transferred to the working fluid in the BPG (i.e., $Q_{\mathrm{BPG}}$ ). These values still account for heat loss from the SHX and warm solution lines.

$$
\mathrm{COP}_{\text {int }}=Q_{\text {evap }} / Q_{\mathrm{BPG}}
$$

Internal COP values are higher, with representative main test matrix values of: $\sim 0.06 \pm 0.01$ $\left(T_{\text {evap,CF }}=6 \rightarrow 3^{\circ} \mathrm{C}\right), 0.14 \pm 0.02\left(12 \rightarrow 8^{\circ} \mathrm{C}\right), 0.17 \pm 0.02\left(18 \rightarrow 14^{\circ} \mathrm{C}\right)$. Uncertainties for $\mathrm{COP}_{\text {int }}$ are slightly greater than those for $\mathrm{COP}_{\text {ext }}$ due to the high (25\%) uncertainty applied to $R_{\mathrm{BPG}, \mathrm{CF} \text {,amb, }}$ as discussed previously. 
Overall energy balances are applied to the DAR system.

$$
Q_{\text {net }}=Q_{\mathrm{BPG}, \mathrm{CF}}-Q_{\mathrm{BPG}, \mathrm{loss}}-Q_{\text {cond }}+Q_{\text {evap }}-Q_{\mathrm{BPG}-\mathrm{SHX}, \text { loss }}-Q_{\mathrm{SHX}, \mathrm{loss}}-Q_{\text {sub }}-Q_{\mathrm{abs}}
$$

Here, $Q_{\text {BPG-SHX,loss }}$ is the heat loss in the connective plumbing from the BPG CS outlet to SHX CS inlet $(7.8-13.1 \pm 0.3-0.7 \mathrm{~W})$. Net heat transfer rates in the entire system are $0 \mathrm{~W}$ to within solver precision $\left(\left|Q_{\text {net }}\right|<10^{-9} \mathrm{~W}\right)$, which provides verification for the overall analysis approach.

\section{COMPONENT AND MODEL ASSESSMENT}

\subsection{Bubble-pump generator}

Stable bubble-pump generator (BPG) solution pumping was observed in all experimental

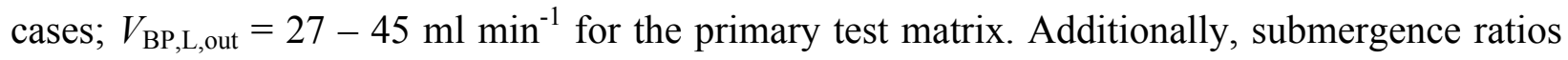
of only $0.255-0.280$ were employed for these cases. This ensured adequate vertical space for the gas-loop components (condenser, evaporator, GHX, absorber), and yielded a liquid head of approximately $1.3 \mathrm{~m}$ to drive flow through the $\mathrm{SHX}$ and absorber. Liquid pumping rates ( $\left.V_{\mathrm{BPG}, \mathrm{L}, \mathrm{out}}\right)$ generally increased with vapor refrigerant flow rates $\left(V_{\mathrm{BPG}, \mathrm{V}, \mathrm{out}}\right)$ for the primary test matrix, varying ambient temperature cases, and varying ambient air velocity cases (Figure 9). The varying ambient pressure cases were not included in Figure 9 because solution saturation temperatures were significantly higher at those conditions. On average, solution flow rates increased slightly with source temperature $\left(T_{\mathrm{BPG}, \mathrm{CF}, \text { in }}\right)$ as predicted in Section 2.2 of Rattner and Garimella (2015b), but variations in submergence ratios between cases $(0.255-0.280)$ made it difficult to isolate this effect. Still, these results indicate that low source temperatures $\left(\sim 110^{\circ} \mathrm{C}\right)$ can be employed without significantly degrading BPG performance. 


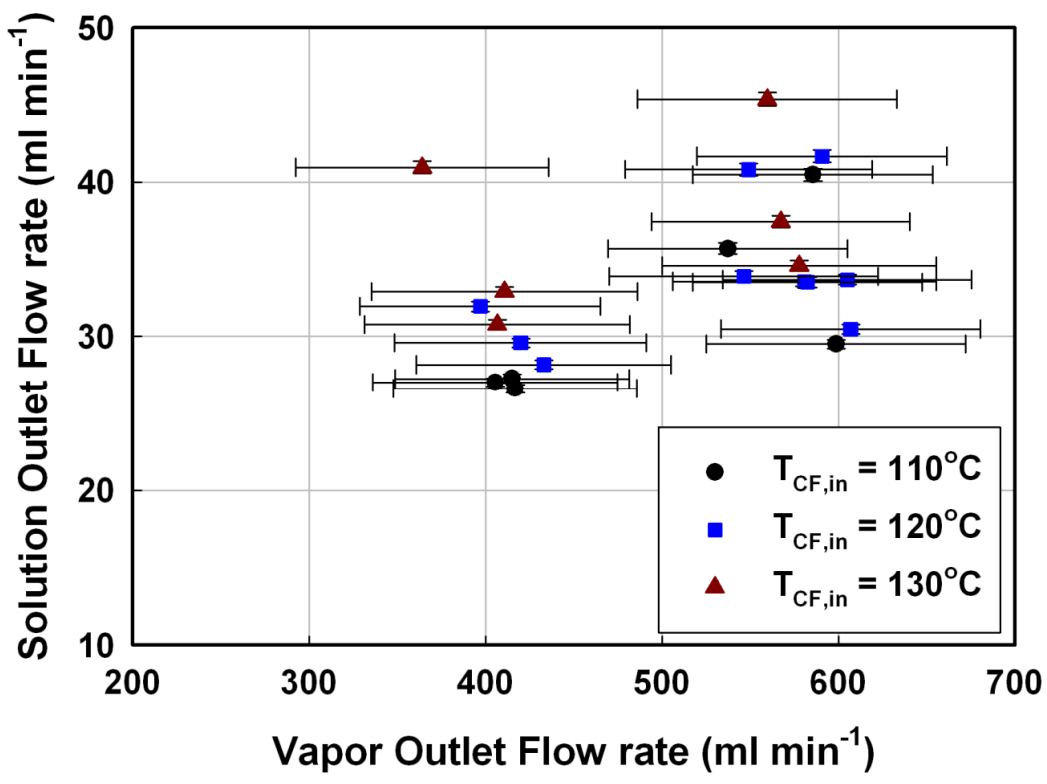

Figure $9-\quad$ Bubble-pump generator concentrated solution and vapor outlet flow rates for the primary test matrix, varying ambient temperature cases, and varying ambient air velocity cases

The major limitation of the proposed BPG design is the relatively high heat loss rate ( $\sim 40 \pm$ $10 \mathrm{~W})$. For the experimental cases, this results in a $25-30 \%$ external COP penalty. The $\mathrm{OD}_{\mathrm{o}}=$ $9.5 \mathrm{~mm}$ BPG was insulated with OD $\sim 100 \mathrm{~mm}$ of fiberglass wrap. Modeling results suggest that only minimal heat loss reductions could be achieved with additional insulation. More compact designs for other components could enable a shorter BPG, and thus, decreased heat loss rates $\left(Q_{\mathrm{Loss}} \sim L_{\mathrm{BPG}}\right)$. In a packaged system, relatively hot components, such as the BPG, SHX, and reservoir could also be integrated to reduce exterior area and heat loss from plumbing.

Experimental data from all cases were employed as inputs for the BPG model described by Rattner and Garimella (2015b). If measured solution outlet flow rates are specified $\left(m_{\mathrm{CS}}\right)$, model predictions for submergence ratios $\left(S_{\mathrm{r}}\right)$ agree with experimental results with an average absolute deviation of $11 \%\left(A A D=(1 / n) \sum_{n}\left(S_{\mathrm{r}, \bmod }-S_{\mathrm{r}, \text { exp }}\right) / S_{\mathrm{r}, \text { exp }}\right)$. In general, the proposed model under- 
predicts $S_{\mathrm{r}}$ (average of 0.029 under-prediction of $S_{\mathrm{r}}$, or equivalently $\sim 270 \mathrm{~Pa}$ in BPG driving pressure). This may be due to pressure drops in the solution heat exchanger and connective plumbing from the reservoir to the BPG inlet (not accounted for in the model). Additionally, material property correlations for $\mathrm{NH}_{3}-\mathrm{NaSCN}$ are based on a limited database of measurements (Infante Ferreira, 1984). No solution viscosity data are available for the conditions in the BPG, and no surface tension data are available for the mixture. The overall model performance is acceptable considering these factors.

On average, the proposed BPG model predicts refrigerant flow rates to within $0.1 \mathrm{~g} \mathrm{~min}^{-1}$ of experimental values $\left(m_{\mathrm{ref}}=2.5-4.2 \pm 0.5 \mathrm{~g} \mathrm{~min}^{-1}\right)$. Average errors for the outlet coupling fluid ( $\left.T_{\mathrm{BPG}, \mathrm{CF}, \text { out }}\right)$ and working fluid $\left(T_{\mathrm{BPG}, \text { out }}\right)$ temperatures are $0.8 \mathrm{~K}$ and $2.1 \mathrm{~K}$, respectively. Average concentrated solution concentration $\left(\psi_{\mathrm{CS}}\right)$ errors are 0.007 (experimental uncertainty \pm 0.001 ). Average errors for total CF heat transfer $\left(Q_{\mathrm{BPG}, \mathrm{CF}}\right)$ and $\mathrm{BPG}$ heating rates $\left(Q_{\mathrm{BPG}}\right)$ are $4.8 \mathrm{~W}$ and $3.4 \mathrm{~W}$, respectively. Corresponding experimental uncertainties are $1-4 \mathrm{~W}$ and $9-12 \mathrm{~W}$, respectively. This indicates that the proposed model captures the overall behavior of the BPG, in addition to the liquid pumping performance. For some parameters, discrepancies are significantly less than experimental uncertainties. This is primarily an artifact of the BPG heat loss model, for which the same assumptions for $R_{\mathrm{BPG}, \mathrm{CF}, \mathrm{amb}}$ and $Q_{\mathrm{BPG}, \text { loss }}$ are employed in the model and experimental data reduction procedure.

If submergence ratios are supplied to the proposed model as inputs (rather than $m_{\mathrm{CS}}$ ), then predictions for solution pumping rates significantly exceed experimental measurements $(\mathrm{AAD}=$ $56 \%$ ). This large discrepancy is a result of the numerical conditioning of the BPG design problem, for which small changes in $S_{\mathrm{r}}$ yield large changes in $m_{\mathrm{CS}}$. Improved model performance may not be possible at present due to the limited fluid property data available in the literature. As 
indicated above, predicted and measured liquid pumping rates can be brought into agreement with submergence ratio $\left(S_{\mathrm{r}}\right)$ adjustments of only 0.03 on average. From the perspective of DAR system design, the proposed model is acceptable because only minor charge adjustments are required during system commissioning to achieve target flow rates.

\subsection{Condenser}

It is difficult to rigorously assess the condenser performance using available experimental data $\left(m_{\text {ref, }}, T_{\text {cond,in }}, T_{\text {cond,out }}\right)$. In all cases, complete condensation $\left(T_{\text {sat }}-T_{\text {cond,out }}=4.4 \mathrm{~K}\right.$ on average $)$ and close approach to ambient temperatures $\left(\mathrm{CAT}_{\text {cond }}=T_{\text {cond,out }}-T_{\text {amb }}=-1.0 \mathrm{~K}\right.$ on average) were observed. As indicated in Section 2.3, negative $\mathrm{CAT}_{\text {cond }}$ values may be due to local ambient air-temperature variations or proximity of the condenser outlet thermocouple to the evaporator core. This indicates that the proposed condenser design is acceptable, or even oversized for this application.

Local upward ambient air velocities were measured with a handheld anemometer, and varied over $U_{\text {amb }}=0.2-0.8 \mathrm{~m} \mathrm{~s}^{-1}$ in the ventilation hood $\left(0.5 \mathrm{~m} \mathrm{~s}^{-1}\right.$ near the condenser $)$ for the primary test matrix. The model formulated in Section 2.3 of Rattner and Garimella (2015b) predicts complete condensation for almost all of these cases with ambient velocities of $0.10-0.45 \mathrm{~m} \mathrm{~s}^{-1}$ (two cases require greater $U_{\mathrm{amb}}$ ). These results indicate general validity of the proposed model. At reduced ventilation rates $(50 \%)$, measured velocities varied over $0.0-0.4 \mathrm{~m} \mathrm{~s}^{-1}\left(0.4 \mathrm{~m} \mathrm{~s}^{-1}\right.$ near the condenser). The condenser model predicts a required ambient air circulation rate of 0.52 $\mathrm{m} \mathrm{s}^{-1}$ for the experimental case measured at these conditions. No velocity readings registered on the anemometer when the hood fan was turned off. The condenser model predicts a required ambient air velocity of $0.13 \mathrm{~m} \mathrm{~s}^{-1}$ for the experimental case evaluated at this condition, which is close to the instrument minimum reading of $0.1 \mathrm{~m} \mathrm{~s}^{-1}$. Overall, these results suggest that the 
proposed condenser model is suitable for overall component sizing. In future studies, additional instrumentation could enable more detailed model assessment and refinement.

\subsection{Evaporator}

Evaporator cooling rates were generally in the range of $Q_{\text {evap }}=5-20 \mathrm{~W}$ for the primary test matrix. These results correspond to only $17-35 \%$ evaporation of refrigerant. It may be possible to increase system performance with a larger (longer) evaporator or improved refrigerant film wetting-promotion techniques. The evaporator was sized to fit between the condenser and GHX, while yielding acceptable gas-phase flow resistance. Therefore, in future design iterations, these components may also have to be modified to accommodate changes in the evaporator configuration.

The evaporator model presented in Section 2.4 of Rattner and Garimella (2015b) requires inputs of $W F$ (the portion of the tube area effectively wetted by refrigerant liquid), auxiliary gas flow rate, and auxiliary gas concentration. It is not possible to rigorously assess the proposed model because these three parameters could not be directly measured. However, the evaporator model can still be applied to qualitatively assess the experimental component performance. If the measured evaporator cooling rate is provided as a model input, the effective value of $W F$ can be determined. For the experimental cases, on average, the inferred wetting factor is $24 \%$, and cooling capacity indicates only $30 \%$ evaporation of refrigerant. Inferred $W F$ values are plotted against refrigerant flow rates $\left(m_{\text {ref }}\right)$ in Figure 10. The effective film wetting area tends to increase with liquid refrigerant flow rate, as would be expected for the transition from rivulet to fallingfilm flow. Based on these results, the evaporator is mass-transfer area limited, and performance could be significantly improved by refining the liquid film distribution mechanism (currently a woven fiberglass sleeve) or increasing the component length as suggested above. 


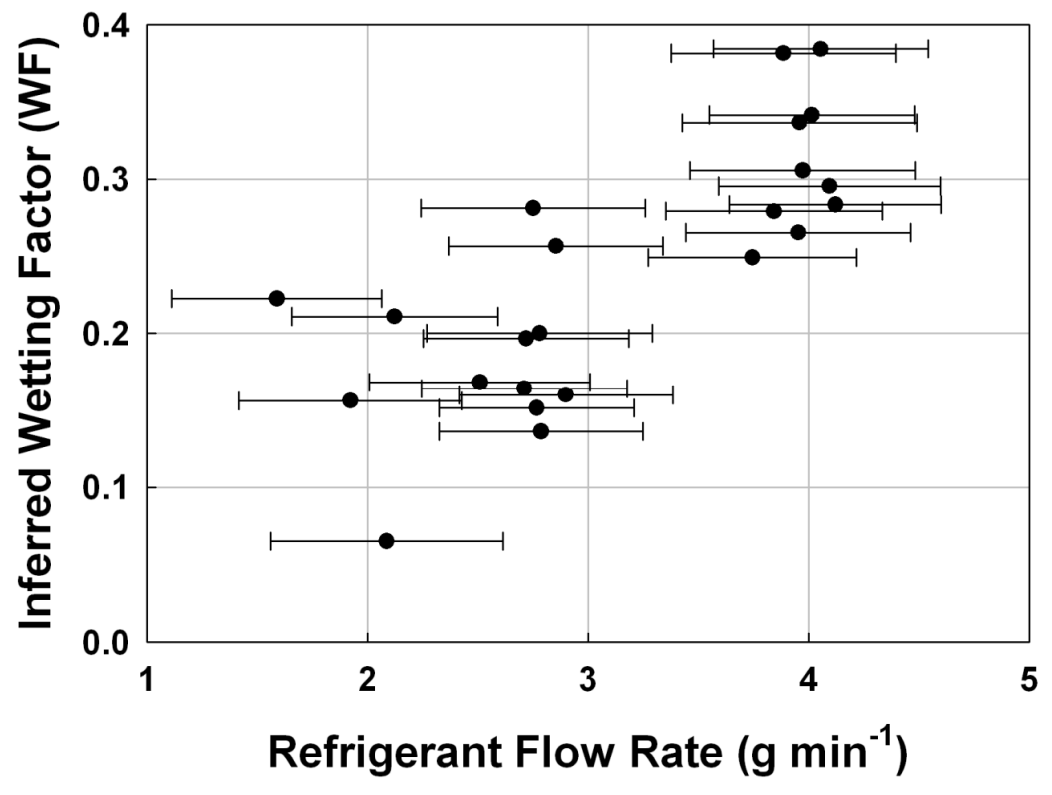

Figure $10-\quad$ Effect of refrigerant flow rate on inferred evaporator wetting factor $(W F)$

Employing the same approach, the design model can be used to quantify the evaporator mass transfer conductance $\left(\mathrm{UA}^{*}\right.$ evap$)$. This quantity is defined as $\mathrm{UA}_{\text {evap }}=m_{\text {evap }} / \mathrm{LMPD}_{\text {evap }}$, where $\mathrm{LMPD}_{\text {evap }}$ is the log-mean vapor pressure difference between the gas mixture and liquid refrigerant streams. For the lower $\left(Q_{\mathrm{BPG}} \sim 90 \mathrm{~W}\right)$ and higher $\left(Q_{\mathrm{BPG}} \sim 120 \mathrm{~W}\right)$ heating rate cases in the main test matrix, $\mathrm{UA}^{*}$ evap ranges over $3.5-5.0 \times 10^{-11} \mathrm{~kg} \mathrm{~Pa}^{-1} \mathrm{~s}^{-1}$ and $5.0-7.5 \times 10^{-11} \mathrm{~kg}$ $\mathrm{Pa}^{-1} \mathrm{~s}^{-1}$, respectively (units of mass flow/vapor pressure difference). These values are approximately $30-60 \%$ of those predicted for complete film-wetting $(W F=1)$ by Rattner and Garimella (2015b).

If $Q_{\text {evap }}$ is provided as a model input, the predicted outlet gas-to-liquid temperature difference $\left(\mathrm{CAT}_{\text {evap,G,L }}=T_{\text {evap,G,out }}-T_{-}\right.$evap,L,out $)$varies with cooling temperature approximately as: $\mathrm{CAT}_{\text {evap, }, \mathrm{L}, \mathrm{L}}\left(T_{\text {evap, } \mathrm{CF}}=6 \rightarrow 3^{\circ} \mathrm{C}\right) \sim 15 \mathrm{~K}, \mathrm{CAT}_{\text {evap, } \mathrm{G}, \mathrm{L}}\left(T_{\text {evap }, \mathrm{CF}}=12 \rightarrow 8^{\circ} \mathrm{C}\right) \sim 12 \mathrm{~K}$, $\mathrm{CAT}_{\text {evap, }, \mathrm{L}}\left(T_{\text {evap, } \mathrm{CF}}=18 \rightarrow 14^{\circ} \mathrm{C}\right) \sim 9 \mathrm{~K}$. This non-equilibrium behavior causes the low-cooling- 
temperature performance penalty to be less severe, because only a portion of the maximum gas sensible cooling load $\left(m_{\mathrm{G}} c_{\mathrm{p}, \mathrm{G}}\left(T_{\text {evap, G,in }}-T_{\text {evap,L,out }}\right)\right)$ is incurred (see Section 2.4 of Rattner and Garimella (2015b)). For example, for the case with $Q_{\mathrm{BPG}}=90 \mathrm{~W}, T_{\mathrm{BPG}, \mathrm{CF}, \mathrm{in}}=130^{\circ} \mathrm{C}, T_{\text {evap }, \mathrm{CF}}=6$ $\rightarrow 3^{\circ} \mathrm{C}$, and $Q_{\text {evap }}=6.5 \mathrm{~W}$, the model predicts $T_{\text {evap,G,out }}=18.5^{\circ} \mathrm{C}$ and $T_{\text {evap, }, \text { out }}=3.1{ }^{\circ} \mathrm{C}$. The evaporator outlet thermocouple measured $9.9^{\circ} \mathrm{C}$ for this case, which is between these two values. However, if the evaporator outlet flow was actually in equilibrium at $9.9^{\circ} \mathrm{C}$, then it would not be

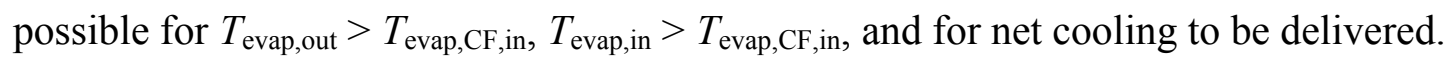

\subsection{Gas heat exchanger}

The gas heat exchanger (GHX) meets the design objective of achieving a significant reduction in the auxiliary gas stream temperatures. Measured auxiliary gas temperature drops $\left(T_{\mathrm{GHX}, \mathrm{o}, \mathrm{in}}-T_{\mathrm{GHX}, \mathrm{o}, \mathrm{out}}\right)$ range over $7.6-14.5 \mathrm{~K}$. Cold-side stream temperature rises $(6.5-9.9 \mathrm{~K})$ are slightly lower, but of similar order to corresponding warm-side values. This indicates that if two-phase flow enters the cold-side of the GHX (as discussed in Section 3.3), only a minor amount of additional evaporative cooling occurs in this component.

Based on overall system results, the gas heat exchanger may in fact be oversized, even with a measured heat exchanger effectiveness of only $31-51 \%$. The evaporator and GHX are installed coaxially between the absorber gas outlet and condenser outlet (Figure 11). If the GHX length is reduced, a larger evaporator could be employed, which may yield an increased refrigerant evaporation fraction (only $17-35 \%$ in this investigation). This approach would increase the evaporator gas inlet temperature, and potentially increase parasitic cooling load. However, based on model results and the discussion in Section 3.3, gas-to-interface thermal resistance is relatively high in the evaporator. Thus, only a small portion of the additional potential parasitic gas cooling load may be incurred. 


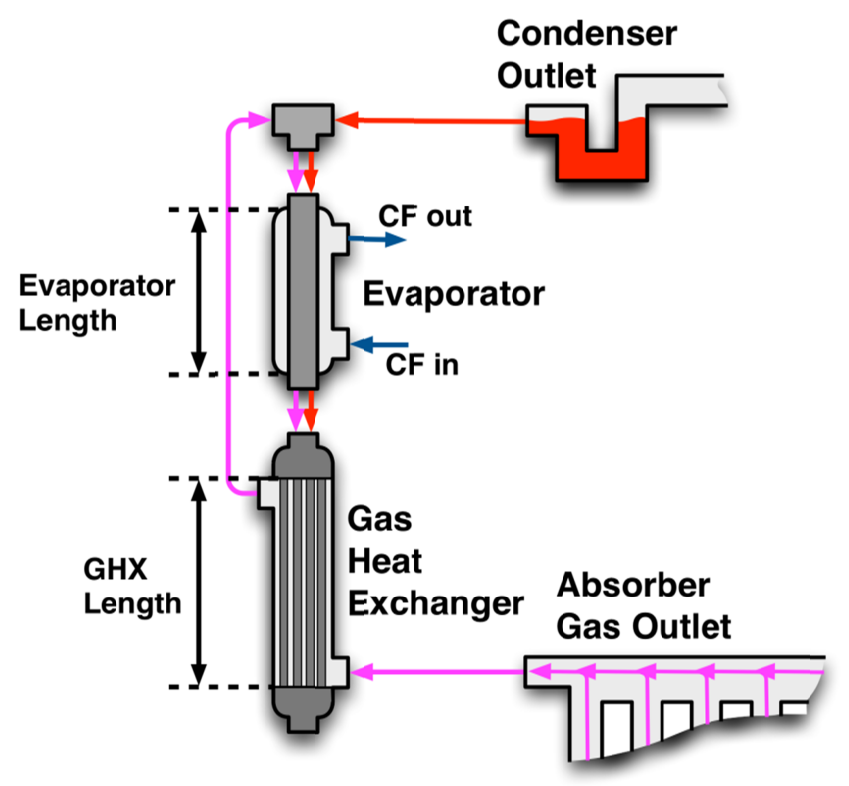

Figure $11-\quad$ Schematic of evaporator and gas heat exchanger installation between the absorber gas outlet and condenser outlet

\subsection{Solution heat exchanger}

The measured solution heat exchanger effectiveness ranges over $\varepsilon_{\mathrm{SHX}}=62-73 \% \pm 2 \%$ ( $\left.\varepsilon_{\mathrm{SHX}}=Q_{\mathrm{SHX}} /\left\{m_{\mathrm{CS}}\left[i_{\mathrm{NH}_{3}-\mathrm{NaSCN}}\left(T_{\mathrm{SHX}, \mathrm{CS}, \mathrm{in}}, \psi_{\mathrm{CS}}\right)-i_{\mathrm{NH}_{3}-\mathrm{NaSCN}}\left(T_{\mathrm{SHX}, \mathrm{DS}, \mathrm{in}}, \psi_{\mathrm{DS}}\right)\right]\right\}\right)$. Here $Q_{\mathrm{SHX}}$ is the net heat gain in the cooler DS stream (i.e., accounting for heat loss to the ambient). The corresponding overall conductances range over $\mathrm{UA}_{\mathrm{SHX}}=2.7-4.8 \pm 0.2 \mathrm{~W} \mathrm{~K}^{-1}$.

Even with relatively thick insulation ( $\sim 50 \mathrm{~mm}$ thick fiberglass panels), a significant amount of heat is lost from the $\operatorname{SHX}\left(Q_{\mathrm{SHX}, \text { loss }}=8-18 \mathrm{~W}, 16-40 \%\right.$ of $\left.Q_{\mathrm{SHX}}\right)$. This corresponds to an effective heat loss coefficient of $\mathrm{UA}_{\mathrm{SHX}, \mathrm{amb}}=0.5-1.0 \pm 0.1 \mathrm{~W} \mathrm{~K}^{-1}$ based on the log-mean temperature difference between the SHX annulus side and ambient.

Increased component length may improve $\mathrm{UA}_{\mathrm{SHX}}$, but would also result in approximately proportional increases in heat loss. Thus, while there is some potential to increase SHX 
performance $\left(\varepsilon_{\mathrm{SHX}}=0.62-0.73\right)$, it may be more productive to focus on improving component packaging and insulation to reduce $\mathrm{UA}_{\mathrm{SHX}, \mathrm{amb}}$ rather than increasing SHX size and $\mathrm{UA}_{\mathrm{SHX}}$.

\subsection{Solution subcooler}

The solution subcooler yields CS temperature reductions of $9-11 \mathrm{~K}$ for the experimental cases, corresponding to $7.4-21.7 \mathrm{~W}$ of heat removal and heat transfer conductances of $\mathrm{UA}_{\text {sub }}=$ $1.5-2.1 \mathrm{~W} \mathrm{~K}^{-1}$. This significantly reduces the required absorber heat rejection capacity, and lowers the absorber inlet solution vapor pressure by $53-118 \mathrm{kPa}$. These results suggest that the inclusion and fin enhancement of the solution subcooler section may improve overall DAR system performance.

\subsection{Absorber}

Measured absorber heat transfer rates vary over $Q_{\mathrm{abs}}=-6.3-12.4 \pm 1-2 \mathrm{~W}$ for the main test matrix. These values are relatively low because of sensible heating of gas and solution in the absorber. As discussed in Section 2.8, negative absorber heat transfer rates occur in some cases due to sensible heating of the cool gas mixture inlet stream $\left(15-23^{\circ} \mathrm{C}\right.$ at the GHX outlet). If sensible solution and gas stream (at $m_{\mathrm{abs}, \mathrm{G}}$ and $\xi_{\mathrm{abs}}$ ) loads are accounted for, then absorber latent heat transfer rates of $24-45 \mathrm{~W}$ are inferred. This range corresponds to absorption of $1.2-2.5 \mathrm{~g}$ $\min ^{-1}$ of ammonia $\left(i_{\mathrm{LV}, \mathrm{NH} 3}=1140 \mathrm{~kJ} \mathrm{~kg}^{-1}\right)$, about twice the inferred evaporator evaporation rates. This suggests that additional phase change occurs in the GHX and connecting plumbing to the absorber gas inlet. However, it is difficult to perform more detailed analysis without precise auxiliary gas flow rate and concentration data and specification of the state of the potentially non-equilibrium two-phase inlet gas-refrigerant matrix.

The absorber and evaporator performances are tightly coupled. In the primary experimental test matrix, cooling rates indicate only $17-35 \%$ evaporation of refrigerant. Some additional 
evaporation occurs between the evaporator outlet and absorber inlet. The remaining refrigerant is assumed to enter the absorber in the liquid state, and mix with the outlet solution stream. If the evaporation rate could be increased, the absorber inlet gas ammonia vapor pressure would rise, resulting in increased absorption. Similarly, if the absorption rate could be increased, the driving vapor pressure difference for evaporation in the evaporator would increase, resulting in greater cooling capacity. Given the relatively low cooling rates (corresponding to $17-35 \%$ of $m_{\mathrm{ref}} \times$ $\left.i_{\mathrm{LV}, \mathrm{NH} 3}\right)$, the evaporator and absorber can be identified as the primary limitations on system performance. Future investigations should thus focus on refining these two components.

If inferred auxiliary gas inlet and outlet states are specified as model inputs (assuming $m_{\mathrm{abs}, \mathrm{G}, \text { in }}=m_{\mathrm{evap}, \mathrm{G}, \text { out }} \xi_{\mathrm{abs}, \mathrm{G}, \text { in }}=\xi_{\text {evap, G,out }}$ and equal flow in all 10 tubes), then inferred film wetting factors range over $W F=0.21-0.61$ ( 0.46 on average). This suggests that incomplete film wetting could be limiting absorber performance. Similarly, if $W F$ is set to 1.0 , then the number of active tubes (i.e., $n_{\text {tubes }}$ such that $\left.Q_{\mathrm{abs}, \bmod }=Q_{\mathrm{abs}, \mathrm{exp}}\right)$ ranges over $2.1-6.8$ (4.7 average). The number of active tubes represents those that receive sufficient liquid from the inlet header. From this perspective, increasing the number of absorber tubes may not improve component performance if working fluid distribution is not also improved. The actual absorber performance is probably limited by a combination of these two factors. Poor liquid distribution may result in liquid rivulet $(W F<1)$ or no-flow $(W F=0)$ in some tubes.

Inferred $W F$ and active tube counts are presented with measured CS flow rates in Figure 12. These plots indicate that component performance improves with increased solution flow rates. This supports the proposed explanations of limited absorber performance, as increased solution flow in each tube would improve liquid film wetting (WF). Similarly, increased solution flow to 


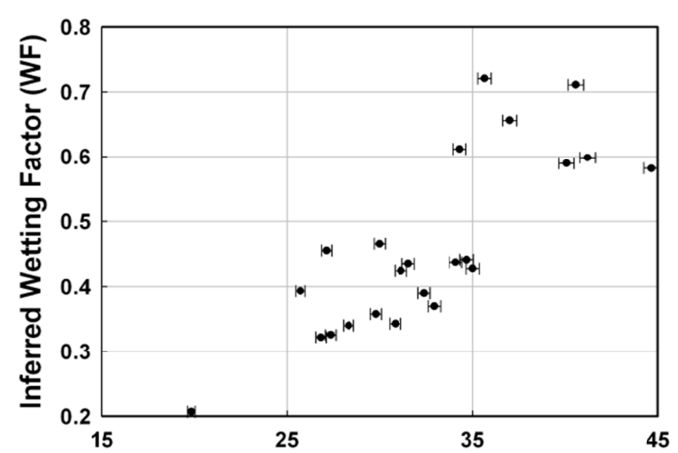

a.

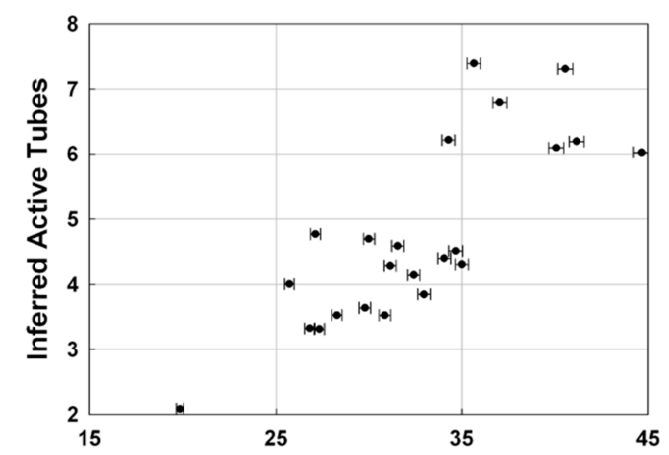

b. Concentrated Solution Flow Rate $\left(\mathrm{g} \mathrm{min}^{-1}\right)$

Figure $12-\quad$ Effect of concentrated solution flow rate on inferred (a) absorber film wetting factor (WF) and (b) number of active absorber tubes $\left(n_{\text {tubes }}\right)$

the upper header would improve liquid distribution between tubes (i.e., not only feeding liquid to tubes closest to the inlet port).

Gas-to-solution mass transfer conductances $\left(\mathrm{UA}^{*}{ }_{\mathrm{abs}}\right)$ for the main test matrix for low and high heating rates $\left(Q_{\mathrm{BPG}}=90 \mathrm{~W}, 120 \mathrm{~W}\right)$ range over $0.7-1.0 \times 10^{-10} \mathrm{~kg} \mathrm{~Pa}^{-1} \mathrm{~s}^{-1}$ and $0.9-1.6 \times$ $10^{-10} \mathrm{~kg} \mathrm{~Pa}^{-1} \mathrm{~s}^{-1}$, respectively. The values are about $30-60 \%$ of those predicted in the design model for uniform solution distribution and film wetting $\left(2.4 \times 10^{-10} \mathrm{~kg} \mathrm{~Pa}^{-1} \mathrm{~s}^{-1}\right.$, Section 2.5 of Rattner and Garimella (2015b)). System performance could potentially be improved by raising the BPG reservoir level to increase solution flow rates. However, in the current experimental system configuration, this would flood the lower absorber header, preventing gas circulation. This approach can be explored in future studies with minor modifications to the experimental facility.

\section{COMPLETE DAR SYSTEM}

External and internal system COP results from the main test matrix are presented in Figure

13. For these cases, the system pressure was $p_{\text {sys }} \sim 1.15 \mathrm{MPa}$, dilute solution (DS) concentration 

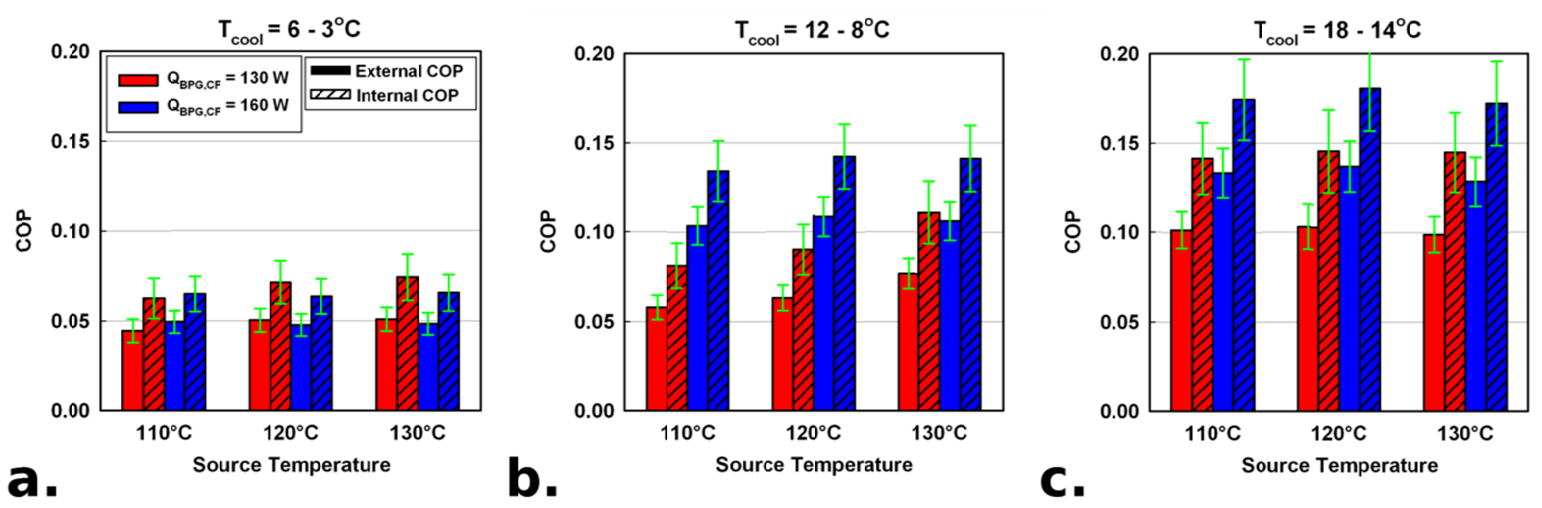

Figure 13 - Internal and external system COP values for the primary test matrix $\left(p_{\text {sys }} \sim 1.15 \mathrm{MPa}, \psi_{\mathrm{DS}} \sim 0.52, T_{\mathrm{amb}} \sim 25^{\circ} \mathrm{C}, U_{\mathrm{amb}}=0.2-0.8 \mathrm{~m} \mathrm{~s}^{-1}\right)$ for evaporator coupling fluid temperatures of $T_{\text {evap,CF }}=(\mathbf{a}) 6 \rightarrow 3^{\circ} \mathrm{C}$, (b) $12 \rightarrow 8^{\circ} \mathrm{C}$, (c) $18 \rightarrow 14^{\circ} \mathrm{C}$

was $\psi_{\mathrm{DS}} \sim 0.52$, ambient air temperature was $T_{\mathrm{amb}} \sim 25^{\circ} \mathrm{C}$, and the ambient air-flow velocity varied over $U_{\mathrm{amb}}=0.2-0.8 \mathrm{~m} \mathrm{~s}^{-1}$ in the ventilation hood. Representative internal cooling COPs are: $0.06\left(T_{\text {evap,CF }}=6 \rightarrow 3^{\circ} \mathrm{C}\right), 0.14\left(12 \rightarrow 8^{\circ} \mathrm{C}\right)$, and $0.17\left(18 \rightarrow 14^{\circ} \mathrm{C}\right)$. The intermediate evaporator $\mathrm{CF}$ temperature results are comparable with those from another fully passive lowsource-temperature DAR system reported in the literature $\left(\mathrm{COP}=0.10-0.14\right.$ for $T_{\text {evap,CF }}=9^{\circ} \mathrm{C}$ (Ben Ezzine et al., 2010)). However, it is difficult to make one-to-one comparisons between experimental DAR systems in general, because relative component sizes (and costs) and operating conditions can vary significantly.

System cooling capacity and COPs decrease at lower evaporator temperatures. This occurs because (1) the driving vapor pressure difference for evaporation decreases $\left(p_{\mathrm{sat}, \mathrm{NH} 3}\left(T_{\mathrm{evap}}\right)-\right.$ $\mathrm{P}_{\mathrm{v}, \text { aux }}$ ), and (2) the parasitic liquid refrigerant and auxiliary gas cooling load increases. A minimum evaporator outlet temperature of $-2^{\circ} \mathrm{C}$ was measured with no evaporator $\mathrm{CF}$ circulation. This suggests that the proposed system can also be used for freezing at low COPs. 
The system performance was found to be nearly independent of BPG CF inlet temperature ( $T_{\text {source }}$ ), provided that a minimum temperature for stable operation was exceeded $\left(\sim 110^{\circ} \mathrm{C}\right)$. This result demonstrates the suitability of the proposed DAR system for solar- or waste-heat activated applications, for which source temperatures may vary during operation. It is difficult to isolate the effects of source temperature on system performance. At increased $T_{\text {source, }}$, heat loss rates to the ambient increase slightly. Additionally, the solution flow rate in the BPG increases. This leads to greater sensible heating load and reduced refrigerant generation. However, increased solution flow was found to yield improved absorber performance in Section 3.7. Conversely, refrigerant generation rates increased with decreased $T_{\text {source. }}$. This was found to improve evaporator performance in Section 3.3. These competing effects may cause the relatively low sensitivity of COP to $T_{\text {source. }}$.

In this investigation, system performance was found to consistently decrease with lower input heating rates. This result may initially seem counter-intuitive, because thermal system efficiencies usually decrease with increasing load as the individual heat and mass exchangers become effectively "under-sized". However, in the proposed system, flow distribution and film wetting in the evaporator and absorber have been identified as key limitations on system performance. Based on results from Sections 3.3 and 3.7, reduced flow rates can severely inhibit operation of these components. For example, at very low solution flow rates, almost all DS may flow through the absorber tubes closest to the liquid inlet, yielding minimal interfacial area. Additionally, in the proposed system, heat loss rates primarily depend on operating temperatures and not heat transfer rates. Thus, relative heat loss rates from the solution plumbing and SHX and heat gain rates in the evaporator and GHX may be more significant at reduced system capacity. Similarly, the relative internal-to-external COP penalties are more severe at reduced 

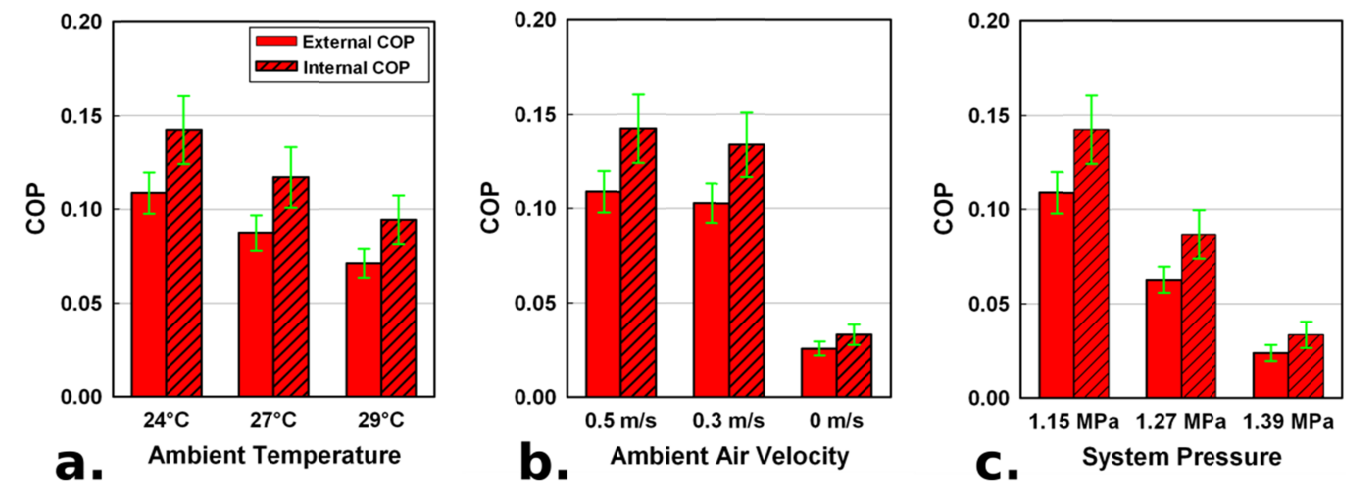

Figure 14 - Internal and external system COP values for the off-design condition test matrices $\left(T_{\mathrm{BPG}, \mathrm{CF}, \mathrm{in}}=120^{\circ} \mathrm{C}\left(130^{\circ} \mathrm{C}\right.\right.$ for elevated $p_{\text {sys }}$ cases $)$, $Q_{\mathrm{BPG}, \mathrm{CF}}=160 \mathrm{~W}$, and $T_{\text {evap,CF }}=12 \rightarrow 8^{\circ} \mathrm{C}$ ) with (a) Varying ambient temperature, (b) Varying ambient air vertical velocity, (c) Varying system pressure

thermal input rates $\left(\left(\mathrm{COP}_{\text {int }}-\mathrm{COP}_{\mathrm{ext}}\right) / \mathrm{COP}_{\text {int }} \sim 40 \%\right.$ at $Q_{\mathrm{BPG}, \mathrm{CF}} \sim 120 \mathrm{~W}$, and $\sim 30 \%$ at $Q_{\mathrm{BPG}, \mathrm{CF}}=$ $160 \mathrm{~W})$.

Results from the off-design-condition test matrices (varying $T_{\mathrm{amb}}, U_{\mathrm{amb}}, p_{\mathrm{sys}}$ ) are presented in Figure 14 . For these cases, $T_{\mathrm{BPG}, \mathrm{CF}, \text { in }}=120^{\circ} \mathrm{C}\left(130^{\circ} \mathrm{C}\right.$ for elevated $p_{\text {sys }}$ cases $), Q_{\mathrm{BPG}, \mathrm{CF}}=160 \mathrm{~W}$, and $T_{\text {evap,cf }}=12 \rightarrow 8^{\circ} \mathrm{C}$. System performance is found to steadily decrease with increasing average ambient temperature (Figure 14a), with $\mathrm{COP}_{\mathrm{int}}=0.142 \rightarrow 0.094$ for $T_{\mathrm{amb}}=24 \rightarrow 29^{\circ} \mathrm{C}$. This trend is commonly found in cooling systems, and is due to a combination of factors. Elevated ambient temperatures cause increased condenser outlet/evaporator refrigerant inlet temperatures $\left(23.0,24.2,26.5^{\circ} \mathrm{C}\right.$ for these cases $)$. This leads to increased parasitic refrigerant cooling load. As noted in Section 2.3, condenser outlet temperatures were found to be slightly below measured average ambient temperatures in many cases, possibly due to fluctuations in air temperature or proximity to the cold evaporator core. Additionally, elevated ambient temperatures cause reduced driving temperature differences for solution subcooler and absorber 
heat rejection. For these three increasing $T_{\text {amb }}$ cases, the subcooler outlet temperatures were 27.9, 32.9, and $33.8^{\circ} \mathrm{C}$, respectively. Finally, the elevated system pressure at high $T_{\text {amb }}$ resulted in reduced solution flow in the BPG $\left(T_{\text {amb }}=24^{\circ} \mathrm{C}: p_{\text {sys }}=1.15 \mathrm{MPa}\right.$ and $m_{\mathrm{CS}}=34.8 \mathrm{~g} \mathrm{~min}^{-1}, T_{\mathrm{amb}}=$ $29^{\circ} \mathrm{C}: p_{\mathrm{sys}}=1.18 \mathrm{MPa}$ and $\left.m_{\mathrm{CS}}=30.5 \mathrm{~g} \mathrm{~min}^{-1}\right)$. This could cause reduced absorber performance.

Reduced ambient air-velocity (Figure 14b) was found to have a minor effect on system performance from $U_{\mathrm{amb}}=0.2-0.8 \mathrm{~m} \mathrm{~s}^{-1}$ to $0-0.4 \mathrm{~m} \mathrm{~s}^{-1}\left(\mathrm{COP}_{\text {int }}=0.142 \rightarrow 0.134\right)$. However, further reduction to negligible ambient air flow severely reduced performance $\left(\mathrm{COP}_{\mathrm{int}}=0.033\right)$. This behavior is consistent with results from the condenser model, which predicts low threshold $U_{\text {amb }}$ values $\left(\sim 0.1-0.2 \mathrm{~m} \mathrm{~s}^{-1}\right)$ below which condensation will be incomplete. Reduced air flow also caused increased ambient temperatures $\left(24.0,25.5,26.1^{\circ} \mathrm{C}\right)$ for these cases because the experimental facility was operated inside a closed ventilation hood. As discussed previously, the resulting elevation in ambient temperature further reduces system performance.

As discussed in Section 2.3 of Rattner and Garimella (2015b), increased system pressure may be required to ensure complete condensation if ambient cooling is limited. The effect of system pressure $\left(p_{\text {sys }}\right)$ on performance is presented in Figure $14 \mathrm{c}$. Elevated $p_{\text {sys }}$ is found to sharply reduce COPs, with: $\mathrm{COP}_{\text {int }}(1.15 \mathrm{MPa})=0.142, \mathrm{COP}_{\text {int }}(1.27 \mathrm{MPa})=0.087$, and $\mathrm{COP}_{\text {int }}(1.39 \mathrm{MPa})=$ 0.034. The system charge was not varied during this parametric study. Thus, solution saturation temperatures increased with $p_{\text {sys. }}$ For these three cases, the BPG solution outlet temperature increased from $89.1 \rightarrow 98.2 \rightarrow 106.3^{\circ} \mathrm{C}$. This resulted in increased sensible heating load, increased heat loss rates (greater temperature difference to the ambient), and reduced solution pumping rates because $T_{\mathrm{BPG}, \mathrm{CF}, \text { in }}$ was fixed at $130^{\circ} \mathrm{C}\left(V_{\mathrm{CS}}=45.4 \rightarrow 25.0 \rightarrow 18.9 \mathrm{ml} \mathrm{min}^{-1}\right)$. These factors may have all contributed to reduced system performance. Elevated system pressure increases the driving vapor pressure difference for absorption $\left(p_{\mathrm{v}, \mathrm{abs}, \mathrm{G}}-p_{\mathrm{v}, \mathrm{NH} 3-\mathrm{NaSCN}}\left(T_{\mathrm{abs}, \mathrm{L}}\right.\right.$, 
$\left.\left.\psi_{\text {abs, } \mathrm{L}}\right)\right)$, but also reduces the driving vapor pressure for evaporation $\left(p_{\mathrm{sat}, \mathrm{NH} 3}\left(T_{\mathrm{evap}, \mathrm{L}}\right)-p_{\mathrm{v}, \mathrm{evap}, \mathrm{G}}\right)$. Thus, the evaporator and absorber effects may compensate for each other.

The full DAR cycle model proposed in Section 3 of the accompanying paper (Rattner and Garimella, 2015b) is assessed with experimental results from the main and elevated ambient temperature test matrices. For this analysis, the following measured parameters are provided as model inputs: BPG heat input $\left(Q_{\mathrm{BPG}}\right)$, dilute solution concentration $\left(\psi_{\mathrm{DS}}\right)$, system pressure $\left(p_{\mathrm{sys}}\right)$, average cooling delivery temperature $\left(T_{\text {cool }}=\left(T_{\text {evap }, \mathrm{CF}, \text { in }}+T_{\text {evap, }, \mathrm{CF}, \text { out }}\right) / 2\right)$, average ambient temperature $\left(T_{\mathrm{amb}}\right)$, CS flow rate $\left(m_{\mathrm{CS}}\right)$, and auxiliary gas flow rate $\left(m_{\mathrm{aux}}\right)$.The solution and auxiliary gas flow rates could be predicted as part of the cycle analysis using proposed submodels. However, these quantities are very sensitive to system configuration and operating conditions (e.g., solution reservoir level, minor losses in gas-loop plumbing). Therefore, experimental values were employed for $m_{\mathrm{CS}}$ and $m_{\mathrm{aux}}$. Closure parameters are selected based on results from the individual component analyses presented in Section 3 (Table 2). Absorber and evaporator mass transfer conductances (UA* $\left.{ }_{\text {evap }}, \mathrm{UA}^{*}{ }_{\text {abs }}\right)$ are specified based on the input heating rate $\left(Q_{\mathrm{BPG}}\right)$ due to the high sensitivities to refrigerant and solution flow rates, respectively. Similarly, the evaporator outlet gas-to-liquid refrigerant approach temperature $\left(\mathrm{CAT}_{\text {evap, }, \mathrm{L}, \mathrm{L}}\right)$ is specified as a function of the cooling delivery temperature $\left(T_{\text {cool }}\right)$. 
Table 2 - Closure parameters for full system model

\begin{tabular}{|c|c|c|}
\hline Parameter & Definition & Value \\
\hline $\mathrm{CAT}_{\text {cond }}$ & $T_{\text {cond,out }}-T_{\text {amb }}$ & $1 \mathrm{~K}$ \\
\hline $\mathrm{CAT}_{\text {evap }}$ & $T_{\text {cool }}-T_{\text {evap,L,out }}$ & $2 \mathrm{~K}$ \\
\hline $\mathrm{UA}_{\text {evap }}$ & $m_{\text {evap }} / \mathrm{LMPD}_{\text {evap }}$ & $\begin{array}{l}4.0 \times 10^{-11} \mathrm{~kg} \mathrm{~Pa}^{-1} \mathrm{~s}^{-1}\left(Q_{\mathrm{BPG}}=90 \mathrm{~W}\right) \\
5.5 \times 10^{-11} \mathrm{~kg} \mathrm{~Pa}^{-1} \mathrm{~s}^{-1}\left(Q_{\mathrm{BPG}}=120 \mathrm{~W}\right)\end{array}$ \\
\hline $\mathrm{CAT}_{\text {evap,G,L }}$ & $T_{\text {evap,G,out }}-T_{\text {evap,L,out }}$ & $\begin{array}{l}15 \mathrm{~K}\left(T_{\text {cool }}=4.5^{\circ} \mathrm{C}\right) \\
12 \mathrm{~K}\left(T_{\text {cool }}=10.0^{\circ} \mathrm{C}\right) \\
9 \mathrm{~K}\left(T_{\text {cool }}=16.0^{\circ} \mathrm{C}\right)\end{array}$ \\
\hline $\mathrm{UA}_{\mathrm{GHX}}$ & $Q_{\mathrm{GHX}} / \mathrm{LMTD}_{\mathrm{GHX}}$ & $2.0 \mathrm{~W} \mathrm{~K}^{-1}$ \\
\hline $\mathrm{UA}_{\mathrm{SHX}}$ & $Q_{\mathrm{SHX}} / \mathrm{LMTD}_{\mathrm{SHX}}$ & $4.0 \mathrm{~W} \mathrm{~K}^{-1}$ \\
\hline $\mathrm{UA}_{\mathrm{SHX}, \mathrm{amb}}$ & $Q_{\mathrm{SHX}, \text { loss }} / \mathrm{LMTD}_{\mathrm{SHX}, \mathrm{amb}}$ & $0.7 \mathrm{~W} \mathrm{~K}^{-1}$ \\
\hline $\mathrm{UA}_{\text {sub }}$ & $Q_{\text {sub }} / \mathrm{LMTD}_{\text {sub }}$ & $1.8 \mathrm{~W} \mathrm{~K}^{-1}$ \\
\hline $\mathrm{CAT}_{\mathrm{abs}, \mathrm{amb}}$ & $\begin{array}{l}T_{\mathrm{abs}, \mathrm{G}, \text { out }}-T_{\mathrm{amb}} \\
T_{\mathrm{abs}, \mathrm{L}, \mathrm{out}}-T_{\mathrm{amb}}\end{array}$ & $5 \mathrm{~K}$ \\
\hline $\mathrm{UA}^{*}{ }_{\text {abs }}$ & $m_{\text {abs }} / \mathrm{LMPD}_{\mathrm{abs}}$ & $\begin{array}{l}0.85 \times 10^{-10} \mathrm{~kg} \mathrm{~Pa}^{-1} \mathrm{~s}^{-1}\left(Q_{\mathrm{BPG}}=90 \mathrm{~W}\right) \\
1.30 \times 10^{-10} \mathrm{~kg} \mathrm{~Pa}^{-1} \mathrm{~s}^{-1}\left(Q_{\mathrm{BPG}}=120 \mathrm{~W}\right)\end{array}$ \\
\hline
\end{tabular}

Predicted and measured system COPs are compared for the main and elevated ambient temperature test matrices in Figure 15. An average absolute deviation of $21 \%$ is found between predicted and experimental COP (and $Q_{\text {evap}}$ ) values. Two of the low evaporator temperature case COP values are significantly under-predicted (52\%, 62\% error). However, these relatively large COP errors only correspond to $\sim 5 \mathrm{~W}$ errors in $Q_{\text {evap. }}$ These results demonstrate general global validation of the proposed cycle model (e.g. for COP, $\left.Q_{\text {evap}}\right)$.

Detailed model and experimental results are compared in Table 4 for a representative lowcooling-temperature case with operating conditions summarized in Table 3. For this case, measured and predicted internal COP values are $0.064\left(Q_{\text {evap }}=7.6 \mathrm{~W}\right)$ and $0.063\left(Q_{\text {evap }}=7.5\right.$ W), respectively. Most measured and predicted temperature and component heat transfer rates agree to within $4 \mathrm{~K}$ and $15 \%$, respectively. The measured evaporator working fluid outlet temperature is $6.8^{\circ} \mathrm{C}$. This is between the predicted liquid refrigerant and gas mixture outlet 


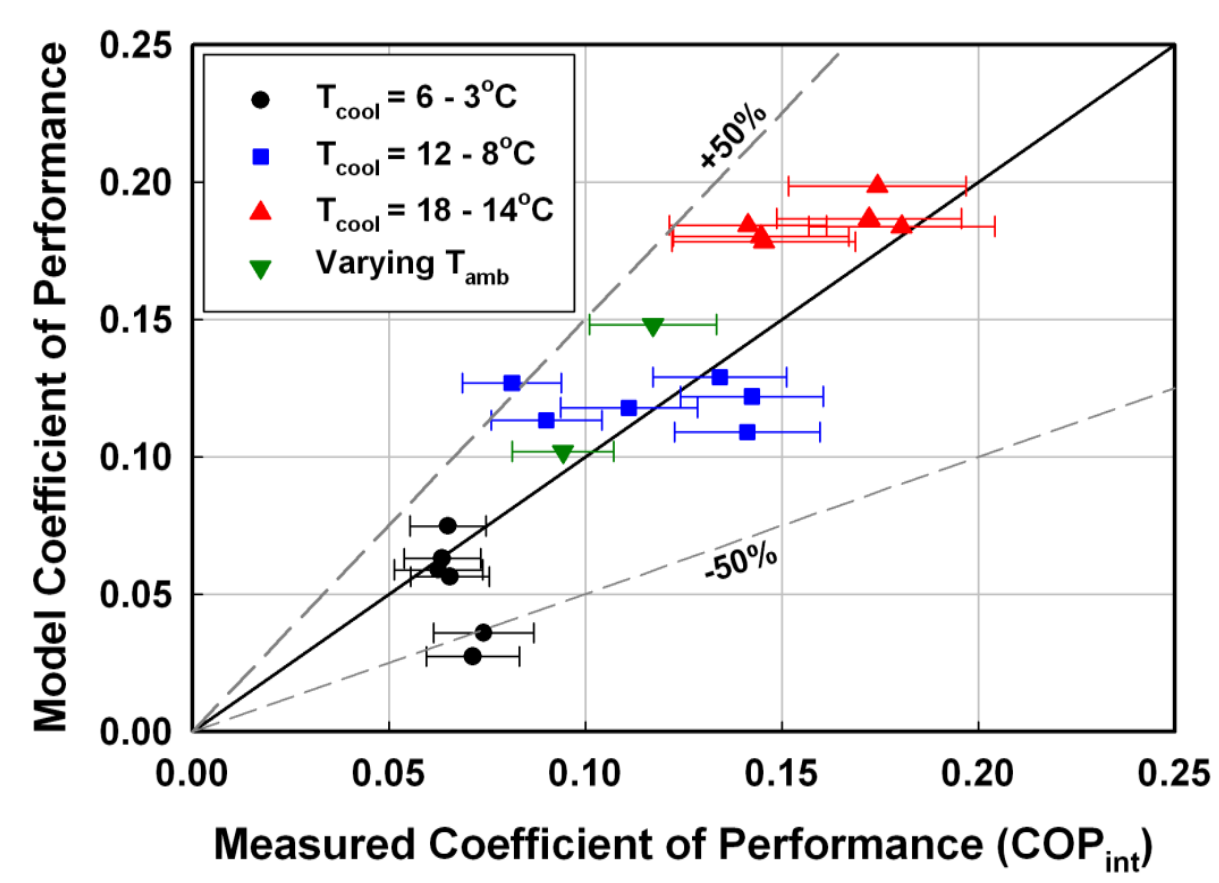

Figure $15-\quad$ Comparison of predicted and measured system internal COPs for the main test matrix and varying ambient temperature test matrix

values of 2.4 and $17.4^{\circ} \mathrm{C}$, respectively. However, it is difficult to compare these temperature values more rigorously without knowing the precise two-phase flow pattern over the thermocouple probe. The measured GHX cold stream outlet temperature is lower than the predicted value $\left(15.8^{\circ} \mathrm{C}\right.$ vs. $\left.24.9^{\circ} \mathrm{C}\right)$. This could be due to non-equilibrium two-phase flow over the outlet thermocouple or a small amount of post-evaporator refrigerant evaporation, which are not considered in the cycle model. As a result, the measured GHX heat transfer rate is $6.7 \mathrm{~W}$ higher than predicted with the model. The potential additional evaporation could cause the greater measured absorber heat rejection rate $(7.9 \mathrm{~W}$ vs. $-0.1 \mathrm{~W})$. The predicted SHX inlet temperature is higher than the measured value $\left(89.8^{\circ} \mathrm{C}\right.$ vs. $\left.81.7^{\circ} \mathrm{C}\right)$. This is due to a small amount of heat loss $(11.6 \mathrm{~W})$ from the connective plumbing between the BPG CS outlet and SHX CS 
Table 3 - Operating conditions for representative low-cooling-temperature case

\begin{tabular}{ll}
\hline Parameter & Value \\
\hline$T_{\text {cool }}$ & $4.5^{\circ} \mathrm{C}$ \\
$Q_{\mathrm{BPG}}$ & $118.9 \mathrm{~W}$ \\
$\psi_{\mathrm{DS}}$ & 0.534 \\
$m_{\mathrm{CS}}$ & $34.1 \mathrm{~g} \mathrm{~min}^{-1}$ \\
$m_{\text {aux }}$ & $38.6 \mathrm{~g} \mathrm{~min}$ \\
$T_{\mathrm{amb}}$ & $25.6^{\circ} \mathrm{C}$ \\
$p_{\text {sys }}$ & $1.14 \mathrm{MPa}$ \\
\hline
\end{tabular}

inlet, which is not considered in the model. The model predicts a SHX heat recovery rate $9.3 \mathrm{~W}$ higher than was measured for the same reason.

Overall, this analysis demonstrates that the proposed cycle model effectively characterizes the overall behavior of the experimental DAR system. Additional sub-models could be incorporated to account for the discrepancies highlighted here. However, the current cycle model already requires many closure parameters to account for multicomponent mixture effects $\left(\mathrm{NH}_{3}\right.$ NaSCN-He), coupled inter-phase heat and mass transfer (evaporator and absorber), and nonequilibrium two-phase flow (evaporator outlet). The potential for increased accuracy should thus be weighed against overall model complexity and robustness. 
Table 4 - Comparison of experimental and model results for the representative low-cooling-temperature conditions

\begin{tabular}{|c|c|c|c|c|}
\hline State Point Temperatures $\left({ }^{\circ} \mathrm{C}\right)$ & Experiment & Model & \multicolumn{2}{|c|}{ Error } \\
\hline Solution reservoir / SHX cool inlet & 34.3 & 30.5 & & 3.9 \\
\hline SHX cool outlet & 63.1 & 64.4 & & 1.4 \\
\hline BPG solution return / SHX hot inlet & 81.7 & 89.8 & & 8.1 \\
\hline SHX hot outlet / Solution subcooler inlet & 40.5 & 42.3 & & 1.8 \\
\hline BPG inlet & 67.0 & 64.4 & & 2.6 \\
\hline BPG outlet & 89.4 & 89.8 & & 0.4 \\
\hline Condenser outlet / Evaporator refrigerant inlet & 24.6 & 26.6 & & 2.0 \\
\hline Evaporator outlet / GHX cool inlet (gas) & 6.8 & 2.4 & & 4.3 \\
\hline Evaporator outlet / GHX cool inlet (liquid) & 6.8 & 17.4 & & 10.6 \\
\hline GHX cool outlet / Absorber gas inlet & 15.8 & 24.9 & & 9.1 \\
\hline Absorber gas outlet / GHX warm inlet & 32.0 & 30.6 & & 1.4 \\
\hline GHX warm outlet & 18.9 & 20.5 & & 1.4 \\
\hline Solution subcooler outlet / Absorber gas inlet & 30.1 & 30.5 & & 0.4 \\
\hline Absorber liquid outlet & 27.2 & 30.6 & & 3.4 \\
\hline Component Heat Transfer (W) & Experiment & Model & \multicolumn{2}{|c|}{ Error } \\
\hline Solution heat exchanger & 50.2 & 59.5 & 9.3 & $(19 \%)$ \\
\hline Solution heat exchanger (heat loss) & 11.1 & 11.4 & 0.3 & $(3 \%)$ \\
\hline BPG solution return (heat loss) & 11.6 & - & & \\
\hline Condenser & 88.5 & 89.8 & 1.4 & $(2 \%)$ \\
\hline Evaporator & 7.6 & 7.5 & 0.1 & $(1 \%)$ \\
\hline GHX & 28.3 & 21.6 & 6.7 & $(24 \%)$ \\
\hline Solution subcooler & 15.3 & 17.3 & 2.0 & $(13 \%)$ \\
\hline Absorber & -0.1 & 7.9 & 7.9 & $(>100 \%)$ \\
\hline Summary & Experiment & Model & \multicolumn{2}{|c|}{ Error } \\
\hline Refrigerant flow rate $\left(\mathrm{g} \mathrm{min}^{-1}\right)$ & 4.0 & 4.1 & & $2.2 \%$ \\
\hline Concentrated solution concentration & 0.597 & 0.598 & & $0.2 \%$ \\
\hline uxiliary gas concentration & 0.334 & 0.339 & & $1.4 \%$ \\
\hline Cooling COP (internal) & 0.064 & 0.063 & & $0.9 \%$ \\
\hline
\end{tabular}




\section{DISCUSSION}

In this investigation, a complete passively cooled low-source-temperature $\left(110-130^{\circ} \mathrm{C}\right)$ DAR system was developed. Cooling was achieved at temperature ranges suitable for refrigeration $\left(T_{\text {evap,CF }}=6 \rightarrow 3^{\circ} \mathrm{C}, \mathrm{COP}_{\text {int }} \sim 0.06\right)$ and air-conditioning $\left(12 \rightarrow 8^{\circ} \mathrm{C}, \mathrm{COP}_{\text {int }} \sim 0.14\right.$; $\left.18 \rightarrow 14^{\circ} \mathrm{C}, \mathrm{COP}_{\text {int }} \sim 0.17\right)$. The DAR system was also evaluated at off-design conditions. A $34 \%$ reduction in internal system $\mathrm{COP}$ was measured for $T_{\mathrm{amb}}=24 \rightarrow 29^{\circ} \mathrm{C}$. Minimal performance penalties were found with reduced ambient air velocity from $0.2-0.8 \rightarrow 0.0-0.4$ $\mathrm{m} \mathrm{s}^{-1}$. However, COP sharply reduced for $U_{\mathrm{amb}} \rightarrow 0$, indicating that some minimal ambient air circulation is necessary for operation. At such limited external cooling conditions, elevated system pressures may be necessary for condenser operation. However, increased source temperatures are also required for high $p_{\text {sys. }}$ Results from this investigation demonstrated reduced COPs at high system pressures. In future studies, it may be possible to mitigate such penalties by reducing $\mathrm{NaSCN}$ concentration, thus maintaining solution saturation temperatures and required source temperatures near target values $\left(\sim 90^{\circ} \mathrm{C}\right.$ and $\sim 110^{\circ} \mathrm{C}$, respectively).

The system design was based on detailed component-level models formulated by Rattner and Garimella (2015b). BPG measurements generally confirmed sub-model validity (average $S_{\mathrm{r}}$ error $=0.03(\sim 11 \%))$. The condenser delivered complete refrigeration condensation in all cases, as predicted with the design model for low ambient air velocities $\left(U_{\mathrm{amb}} \sim 0.1-0.2 \mathrm{~m} \mathrm{~s}^{-1}\right)$. However, more rigorous validation of the component model was not possible with available measurements (inlet and outlet temperatures and refrigerant flow rate). Measured evaporator cooling rates were supplied as model inputs, and results indicate only $17-35 \%$ evaporation of generated refrigerant. This corresponds to a low average liquid film wetting factor $(W F)$ of $24 \%$. 
Absorber inlet and outlet gas states were supplied as model inputs, and effective wetting factors $(W F=0.46$ average $)$ and numbers of active tubes $\left(n_{\text {tubes }}=4.7\right)$ were determined. Absorber mass transfer conductances were significantly lower than those inferred for uniform fluid distribution and film wetting (experimental: $\mathrm{UA}^{*}{ }_{\text {abs }}=0.7-1.6 \times 10^{-10} \mathrm{~kg} \mathrm{~Pa}^{-1} \mathrm{~s}^{-1} \mathrm{vs}$. uniform model: $\left.2.4 \times 10^{-10} \mathrm{~kg} \mathrm{~Pa}^{-1} \mathrm{~s}^{-1}\right)$. Component $\mathrm{UA}^{*}$ improved with solution flow rate, indicating that it may be possible to improve overall system performance by increasing solution flow rates (increasing $S_{\mathrm{r}}$ ).

GHX temperature measurements were employed to infer auxiliary gas circulation rates ( $\left.m_{\text {aux }}\right)$ and concentrations $\left(\xi_{\text {aux }}\right)$. Overall, the component yielded large gas stream temperature reductions $(7.6-14.5 \mathrm{~K})$. Measured SHX overall conductance values were $\mathrm{UA}_{\mathrm{SHX}} \sim 4.0 \mathrm{~W} \mathrm{~K}^{-1}$, resulting in $32-56 \mathrm{~W}$ of heat recovery. However, $8-18 \mathrm{~W}$ of heat were lost from the component at experimental conditions. Solution subcooler conductances were measured to be $\mathrm{UA}_{\text {sub }} \sim 1.8 \mathrm{~W} \mathrm{~K}^{-1}$, corresponding to concentrated solution temperature reductions of $\sim 10 \mathrm{~K}$.

Component-level results from this experimental study were employed to refine cycle-level model closure parameters. Measured and model COP results generally agreed, with an average absolute deviation of $21 \%$ for the primary test matrix and elevated ambient temperature cases. This demonstrates general applicability of the proposed system-level model, provided that closure parameters are appropriate.

In this investigation, relatively low cooling COPs were measured and predicted for the studied DAR system $\left(\mathrm{COP}_{\text {int }} \sim 0.06\right.$ for refrigeration) compared to other technologies, such as vapor compression (COP $\sim 2-4)$ and two-pressure absorption refrigeration $(\sim 0.5-0.8$ (Herold et al., 1996)). The low COP can be expected, to some extent, for passive operation with only 
relatively low exergy thermal input. However, results from this investigation indicate that the system performance is primarily transport limited, rather than being limited by fundamental thermodynamic requirements. For the representative model case presented in Table 4, the predicted cooling capacity is $7.5 \mathrm{~W}$ corresponding to a COP of 0.063 and evaporation of only $25 \%$ of generated refrigerant. If the evaporator and absorber mass transfer conductances are both increased five-fold to $2.8 \times 10^{-10}$ and $6.5 \times 10^{-10} \mathrm{~kg} \mathrm{~s}^{-1} \mathrm{~Pa}^{-1}$, respectively, with all other input parameters held fixed, then the predicted cooling capacity increases approximately ten-fold to $70.5 \mathrm{~W}$. This corresponds to almost complete refrigerant evaporation (99.5\%). The resulting COP $(0.593)$ is comparable to that of two-pressure absorption systems. Thus, there is the potential for major efficiency advances for low-source-temperature DAR technology, but significant engineering challenges must be overcome.

Uncertainties in system operating conditions and fluid properties were significant challenges in this investigation. System instrumentation included solution flow meters, pressure transducers, sight glasses, and thermocouples. However, no instruments were commercially available to measure the auxiliary gas circulation rate. Auxiliary gas concentration could be measured with techniques such as gas-chromatography, but this would significantly increase experimental system costs. In future investigations, special-purpose thermal anemometers and time-of-flight ultrasonic concentration measurement instruments could be employed to determine these quantities. Such detailed information will enable improved assessment of gas-loop components and models.

Modeling results indicate that the refrigerant and auxiliary gas mixture flowing from the evaporator to the absorber was two-phase and far from thermal equilibrium $\left(T_{\mathrm{G}}-T_{\mathrm{L}} \sim 15 \mathrm{~K}\right.$ in some cases). It was therefore difficult to interpret temperature measurements of this stream. In 
future studies, it may be possible to install multiple thermocouples at different cross-sectional locations in this flow path to collect distinct liquid and gas phase measurements.

Limited transport property data are available for the $\mathrm{NH}_{3}-\mathrm{NaSCN}$ solution. No surface tension data have been reported and viscosity measurements are not available for the high temperature conditions in the bubble-pump generator. Thus, additional investigations are needed to determine fluid properties.

Another challenge arose in prediction of coupled natural convection, forced convection, and radiation heat transfer for the corrugated longitudinal vertical fins employed in the solution subcooler and absorber. This heat transfer enhancement geometry may be advantageous for a variety of passively cooled technologies, but has not been well characterized in the literature. Analyses based on canonical heat transfer configurations (e.g., vertical cylinder, parallel plates) led to substantially different heat transfer predictions (see Section 2.5 of Rattner and Garimella (2015b)). Detailed studies of this heat transfer configuration or other enhancement techniques applicable to DAR systems would be valuable.

\section{CONCLUSIONS}

A complete low-source-temperature $\left(110-130^{\circ} \mathrm{C}\right)$ passively cooled diffusion absorption refrigeration (DAR) system was developed. A new working fluid mixture was employed: $\mathrm{NH}_{3}-$ $\mathrm{NaSCN}-\mathrm{He}$. Cooling was achieved at temperature ranges suitable for refrigeration $\left(T_{\text {evap, } \mathrm{CF}}=6\right.$ $\left.\rightarrow 3 \mathrm{C}, \mathrm{COP}_{\mathrm{int}} \sim 0.06\right)$ and air-conditioning $\left(12 \rightarrow 8^{\circ} \mathrm{C}, \mathrm{COP}_{\mathrm{int}} \sim 0.14 ; 18 \rightarrow 14^{\circ} \mathrm{C}, \mathrm{COP}_{\mathrm{int}} \sim\right.$ 0.17). This demonstrates the potential of low-source-temperature fully passive DAR operation at refrigeration conditions. 
Detailed analyses of individual system components were performed. Results were applied to assess models proposed in the accompanying paper (Rattner and Garimella, 2015b), and general agreement was found for the bubble-pump generator and condenser. Component models were applied to assess the evaporator and absorber, and fluid distribution was identified as a potential limiting factor for system performance. Alternative instrumentation techniques could be developed to enable more rigorous analysis of the condenser and gas-loop components.

The refrigeration system achieved stable performance at target operating conditions. Elevated cooling temperature COP was comparable to that reported for another passive low-sourcetemperature DAR system reported in the literature (Ben Ezzine et al., 2010). The present investigation highlighted a number of pathways to improve system performance.

- Heat loss from the BPG, SHX, and connective plumbing significantly reduced system performance. On average, internal COP values were $\sim 30 \%$ higher than external COP values. It may be possible to achieve significant performance gains by improving system packaging to reduce heat loss from warm components (BPG and SHX) and heat gain to cool components (evaporator and GHX).

- Absorber performance was found to increase significantly with solution flow rate. By adjusting component sizes and configuration, the solution reservoir level $\left(S_{\mathrm{r}}\right)$ could be raised to increase solution flow rate.

- Results from this study indicate that the evaporator was under-sized. It may be possible to improve DAR performance by increasing the evaporator length, and reducing that of the GHX.

- Liquid distribution and film-wetting in the evaporator and absorber were identified as potential factors limiting system performance, especially at low flow rates. By refining fluid 
distribution techniques, improved system performance could be obtained over a wide range of operating conditions.

Thus, while DAR technology has existed for approximately 90 years, there is still potential for new low-source-temperature implementations and substantial efficiency gains.

\section{ACKNOWLEDGEMENTS}

The authors wish to acknowledge generous financial support from the U.S. Department of Energy through the Krell Institute (contract DE-FG02-97ER25308). The authors also wish to acknowledge Hannah Oermann for her assistance in constructing the refrigeration facility and performing experiments. 


\section{REFERENCES}

2001. Hysol Product 608 Product Description Sheet. Loctite Corporation, Rocky Hill, CT.

2012. Electronic Code of Federal Regulations, Title 10, Chapter II, Subchapter D, Part 430. United States Department of Energy, Washington, DC.

2013. Paratherm NF Heat Transfer Fluid. Paratherm Corporation, http:/www.paratherm.com.

Ben Ezzine, N., Garma, R., Bourouis, M., Bellagi, A., 2010. Experimental studies on bubble pump operated diffusion absorption machine based on light hydrocarbons for solar cooling, Renewable Energy 35, 464-470.

Herold, K.E., Radermacher, R., Klein, S.A., 1996. Absorption Chillers and Heat Pumps. CRC Press, Boca Raton, FL.

Infante Ferreira, C.A., 1984. Thermodynamic and physical property data equations for ammonialithium nitrate and ammonia-sodium thiocyanate solutions, Solar Energy 32, 231-236.

Jakob, U., Eicker, U., Schneider, D., Taki, A.H., Cook, M.J., 2008. Simulation and experimental investigation into diffusion absorption cooling machines for air-conditioning applications, Applied Thermal Engineering 28, 1138-1150.

Rattner, A.S., Garimella, S., 2015a. Coupling-fluid heated bubble pump generators: experiments and model development, UHVC Science and Technology for the Built Environment 21, 332-347.

Rattner, A.S., Garimella, S., 2015b. Low-source-temperature diffusion absorption refrigeration. Part I: modeling and cycle analysis, International Journal of Refrigeration (In review).

Wang, H., 2012. A new style solar-driven diffusion absorption refrigerator and its operating characteristics Energy Procedia 18, 681-692. 